Florida State University College of Law

Scholarship Repository

Scholarly Publications

2011

\title{
A Prediction Market for Climate Outcomes
}

Shi-Ling Hsu

Florida State University College of Law

Follow this and additional works at: https://ir.law.fsu.edu/articles

Part of the Environmental Law Commons, Law and Politics Commons, Natural Resources Law Commons, and the Oil, Gas, and Mineral Law Commons

Recommended Citation

Shi-Ling Hsu, A Prediction Market for Climate Outcomes, 83 U. COLO. L. REV. 179 (2011), Available at: https://ir.law.fsu.edu/articles/497

This Article is brought to you for free and open access by Scholarship Repository. It has been accepted for inclusion in Scholarly Publications by an authorized administrator of Scholarship Repository. For more information, please contact efarrell@law.fsu.edu. 


\title{
A PREDICTION MARKET FOR CLIMATE OUTCOMES
}

\author{
SHI-LING HSU*
}

This Article proposes a way of introducing some organization and tractability in climate science, generating more widely credible evaluations of climate science, and imposing some discipline on the processing and interpretation of climate information. I propose a two-part policy instrument consisting of (1) a carbon tax that is indexed to a "basket" of climate outcomes, and (2) a cap-andtrade system of emissions permits that can be redeemed in the future in lieu of paying the carbon tax. The amount of the carbon tax in this proposal (per ton of $\mathrm{CO}_{2}$ ) would be set each year on the basis of some objective, non-manipulable climate indices, such as temperature and mean sea level, and also on the number of certain climate events, such as flood events or droughts, that occurred in the previous year (or some moving average of previous years). I refer to these indices and events as climate outcomes. In addition to a carbon tax rate being set each year, an auction would be held each year for tradable permits to emit a ton of carbon dioxide in separate, specific, future years. That is, in the year 2012, a number of permits to emit in 2013 would be auctioned, as well as a number of permits to emit in 2014, in 2015, and so forth. In the year 2013, some more permits to emit in 2014 would be auctioned, as well as more permits to emit in 2015, 2016, and so forth.

The permits to emit in the future are essentially unitary exemptions from a future carbon tax: An emitter can either pay the carbon tax or surrender an emissions permit to emit in the specific vintage year. Because of this link between the carbon tax and the permit market, the trading price of the

\footnotetext{
* University of British Columbia Faculty of Law. Thanks to Dianna Robertson for excellent research assistance, and thanks to Michael Abramowicz, John Abraham, Ross McKitrick, Andrew Dessler, Xuebin Zhang, Judith Curry, Yoram Margalioth, Kevin Gibson, Martin Smith, and commenters at the First Colloquium on Environmental Scholarship at Vermont Law School, and the attendees at the Environmental Law and Policy Workshop at the Buchman Faculty of Law at Tel Aviv University for their help and comments. This research was supported by funding from Carbon Management Canada.
} 
permits should reflect market expectations of what the carbon tax will be in the future and, concomitantly, expectations of future climate outcomes. The idea is to link the price of tradable permits to future climate outcomes, so that a market is created in which accurate and credible information about future climate conditions are important inputs into the price of permits. The market for tradable permits to emit in the future is essentially a prediction market for climate outcomes. And yet, unlike prediction markets that have been operated or proposed thus far, this prediction market for climate outcomes operates against the backdrop of an actual and substantial tax liability. Whereas prediction markets have heretofore largely involved only recreational trading, this prediction market will operate against a regulatory backdrop and thus will provide much stronger incentives for traders to acquire and trade on information.

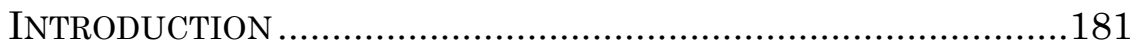

I. Why IS Climate SCIENCE So HARD?............................185

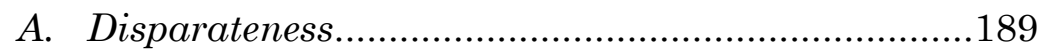

B. Complexity and Uncertainty................................192

C. The Benefits of Denial ..........................................195

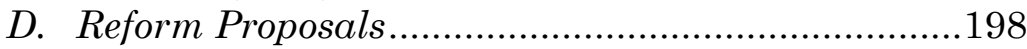

II. PREDICTION MARKETS...........................................200

III. THE TAX-AND-CAP-AND-TRADE PROPOSAL ....................206

IV. IMPLEMENTATION ISSUES AND THE REALPOLITIK OF

CARBON TAXES ….......................................................213

A. Establishing the Carbon Tax................................214

1. Who Is Subject to the Tax?..............................214

2. The Carbon Tax Level.......................................216

3. Which Climate Outcomes? ..............................218

B. The Cap-and-Trade Program ...............................227

1. Initial Allocation of Permits.............................227

2. How Far in Advance Should Permits Be Available? .229

3. How Many Permits Should Be Available for a Vintage Year?.

C. Competitiveness and Trade Concerns ....................2232

D. How Well Will the Market Work? ...........................235

E. What Kinds of Information Will Be Reflected in Trading Activity? 
F. The Politics of Carbon Taxes and Cap-andTrade....

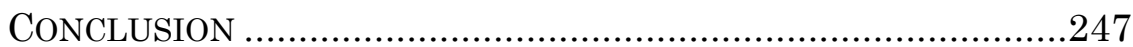

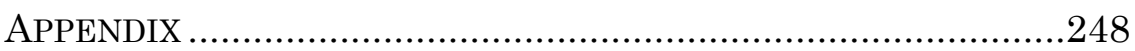

A. Construction of the Carbon Tax Index ...................248

B. Cap-and-Trade Permit Auction Schedule ...............255

\section{INTRODUCTION}

Few challenges in the history of humankind have received as much attention or been the target of as much funding as global climate change. This unprecedented deployment of resources seems warranted, given the potential for vast, sweeping environmental changes that could not only destabilize vital ecosystems but also lead to civil unrest that could politically destabilize entire regions. Climate change is also alone among environmental problems in its extraordinary complexity and inherent uncertainty, therefore requiring a massive research effort. But a spastic outpouring of money has only produced a huge and intractable body of science trying very hard but falling short of predicting future climate conditions. Layered on top of this literature is another set of educated guesses, the variety of possible human response scenarios to climate conditions, which in turn could affect the future climate. ${ }^{1}$ These disparate and complicated bodies of knowledge, products of research efforts at hundreds of universities and research institutes throughout the world, have been foisted upon a hapless global public in desperate need of a "Climate Change for Dummies" manual. ${ }^{2}$

1. Integrated assessment models link climate change effects and economic activity effects in a joint climate and economic model to project climate changes and economic costs and benefits together. For a review of the two dozen or so integrated assessment models, see NiCHOLAS STERN, THE ECONOMICS OF Climate Change: THE STERn REVIEW 164-73 (2007), available at http://www.hmtreasury.gov.uk/stern_review_report.htm; see also Hans-Martin Füssel \& Michael D. Mastrandrea, Integrated Assessment Modeling, in Climate Change SCIEnCE AND POLICY 150, 150-61 (Stephen H. Schneider et al. eds., 2010).

2. One book, Global Warming for Dummies by Elizabeth May and Zoë Caron, is available, but by most indicators, it does not seem to be as popular as one would expect it to be. Elizabeth May is the leader of the Green Party, A Message from Elizabeth May, GREEN PARTY CAN., http://greenparty.ca/leader (last visited Aug. 10, 2011), and Zoë Caron serves on the board of directors for the Sierra Club, 
Into this comprehension vacuum has rushed a variety of interest groups that have helped produce a public discourse that has been at times emotional and vitriolic, and at other times puzzlingly apathetic, but rarely constructive and rarely leading to rational policy discussion. Climate scientists, not generally accustomed to the glare of public policy debate, have found themselves the targets of accusations, investigations, and sometimes death threats. ${ }^{3}$ In this science policy discussion of supreme importance, it is painfully obvious that more heat than light is emerging from the vast amount of climate information available and that the lay public has understandably thrown up its hands and tried to not think about climate change. Climate policy has suffered as a result.

This Article proposes a way of introducing some organization and tractability in climate science, generating more widely credible evaluations of climate science, and imposing some discipline on the processing and interpretation of climate information. I propose a two-part policy instrument-a tax-and-cap-and-trade program consisting of (1) a carbon tax that is indexed to a "basket" of climate outcomes (including, but not limited to, temperatures), and (2) a cap-andtrade system of emissions permits, nested inside this carbon tax, that can be redeemed in lieu of paying the carbon tax. The amount of the carbon tax in this proposal (per ton of carbon dioxide $\left(\mathrm{CO}_{2}\right)$ ) would be set each year on the basis of some objective, non-manipulable climate indices, such as temperature and mean sea level, and also on the measured

Board of Directors, SIERRA CLUB CAN., http://www.sierraclub.ca/en/boarddirectors (last visited Aug. 10, 2011). As of June 26, 2011, the Amazon.com sales rank for the book was 1,095,219, AMAZON.COM, http:/www.amazon.com/GlobalWarming-Dummies-Elizabeth-May/dp/0470840986, as opposed to The Rough Guide to Climate Change by Intergovernmental Panel on Climate Change climate scientist Robert Henson, which ranked 143,368, AMAZON.COM, http://www.amazon.com/Rough-Guide-Climate-Change-2nd/dp/1858281059/ref= sr_1_1?s=books\&ie=UTF8\&qid=1311376968\&sr=1-1, or The Climate Crisis: An Introductory Guide to Climate Change by David Archer and Stefan Rahmstorf, which ranked 24,542, AMAZON.COM, http://www.amazon.com/Climate-CrisisIntroductory-Guide-Change/dp/0521732557/ref=sr_1_1?s=books\&ie=UTF8\&qid= $1311377058 \& \mathrm{sr}=1-1$.

3. See, e.g., Climate Scientists in U.S. Barraged with Death Threats, ClimateWIRE (July 7, 2010), http://www.eenews.net/climatewire/2010/07/07/4 (paid subscription); Climate Scientists Receive Death Threats, ABCNEWS.COM (May 24, 2010), http://abcnews.go.com/WNT/video/climate-scientists-receivedeath-threats-10729457; Stephen Leahy, Violent Backlash Against Climate Scientists, INTER PRESS SERVICE (Mar. 9, 2010), http://ipsnews.net/news.asp?idnews $=50607$. 
severity of certain climate events, such as hurricanes or droughts, that occurred in the preceding year or some moving average of previous years. In addition to a carbon tax rate being set each year, an auction would be held each year for tradable permits to emit a ton of $\mathrm{CO}_{2}$ in separate, specific, future years. That is, in the year 2012, a number of permits to emit in 2013 would be auctioned, as well as a number of permits to emit in 2014 , in 2015, and so forth. In 2013, some more permits to emit in 2014 would be auctioned, as well as more permits to emit in 2015 , and so forth.

The permits to emit in the future are the key to this proposal. Permits would be unitary exemptions from a future carbon tax: An emitter can either pay the carbon tax or surrender an emissions permit to emit in the specific vintage year. Because of this link between the carbon tax and the permit market, the trading price of the permits should reflect market expectations of what the carbon tax will be in the future and, concomitantly, expectations of future climate outcomes. The idea is to link the price of tradable permits to future climate outcomes so that a market is created in which accurate and credible data about future climate conditions are inputs into the price of permits. The market for tradable permits to emit in the future is essentially a prediction market for climate outcomes.

In prediction markets, as in futures markets, contracts are bought and sold in which payoffs are contingent upon specified future outcomes. ${ }^{4}$ The trading prices of contracts thus rise and fall with the perceived probabilities of their occurrence. Prediction markets have a fairly long but inconspicuous history of successfully predicting a variety of outcomes, such as electoral outcomes. ${ }^{5}$ The Iowa Electronic Markets project, ${ }^{6}$ one of the pioneers of prediction markets, has long successfully operated a presidential election market in which "shares" of candidates are bought and sold, their trading price proving to be an accurate predictor of their vote share or the probability of

4. Prediction markets are really an extension of futures markets, with outcomes taking on a broader range of possibilities. While futures markets usually contemplate the delivery of some agricultural commodity or other resource (such as natural gas), shares in a prediction market can be predicated on any outcome.

5. See discussion infra Part II.

6. Tippie Coll. of Bus., The Univ. of Iowa, IowA EleCtronic Markets, http://tippie.uiowa.edu/iem/index.cfm (last visited Feb. 11, 2011) [hereinafter IEM PROJECT]. 
their victory. But this proposal goes well beyond what most prediction markets have thus far tried to accomplish: This proposal creates a prediction market that is connected to an actual regulatory instrument with very substantial financial implications. The indexed carbon tax proposed here, even though quite modest, will give rise to a prediction market of unprecedented size and will create unprecedented incentives for information compilation and revelation.

At the same time, the advantages of prediction markets are uniquely useful in processing climate science. First, the ability of prediction markets to aggregate and organize vast, disparate pieces of information is nowhere employed as productively as in the case of climate change. With climate science coming from so many quarters and drawing on information that is local in many ways, prediction markets are a singularly effective way to process the otherwise intractably numerous bodies of climate science. Second, prediction markets tap into pecuniary self-interest to process information in a way that is presumptively free of bias or preference for certain outcomes. This advantage is of crucial importance in the climate debate, as climate science is in need of not only aggregation and filtering, but also an institution that can scrub out some of the taint of ideology or political manipulation. In the current environment, beliefs about climate change are too intertwined with a variety of economic and professional interests, such that virtually no one can make an assertion about climate change without being accused of having some interest-economic, professional, or psychic-in convincing others. In prediction markets, it is simply too costly to sustain a disingenuous position. It is harder to put your money where your mouth is when you do not truly believe what you are saying, particularly when market prices are providing constant feedback.

This marriage between the idea of prediction markets and the problem of climate science draws out, as marriages should, the best of each partner. There is no better mechanism for processing climate science than prediction markets, and there is no better way to showcase the power of prediction markets than to apply one to climate science. In climate science, prediction markets have found their heretofore highest and best calling, and in prediction markets, climate science has found its redeemer. While this proposal could reduce greenhouse gas emissions, the primary purpose of this proposal 
is not to regulate or price emissions but to create a market that harnesses, processes, and even creates information about climate science in a way that is presumptively free of ideology and bias.

This tax-and-cap-and-trade mechanism also enjoys a political advantage. In this proposal, the carbon tax would be a low one and would increase only if climate change turns out, after all, to be a real problem. By indexing the carbon tax to climate outcomes, it creates a pay-as-you-go policy, requiring payments from carbon emitters as the consequences of their emissions become more tangible and costly. Because the climatic anomalies of climate change will impose costs and in some cases necessitate disaster assistance, the proceeds from the carbon tax and the auction proceeds from the cap-and-trade program can be used to provide this assistance. In this sense, this tax-and-cap-and-trade program is a pay-as-is-needed policy of assistance. Couched as a funding mechanism rather than a revenue-grab, it may be easier to sell to a tax-averse public.

Part I of this Article provides a background of the information problems that have plagued climate science and hampered the development of climate policy. Part II of this Article provides some background theory and practice of prediction markets. Part III sets forth the proposed policy, setting out the details of the policy proposal, along with some rationales for the many micro-decisions that need to be made for this proposal to work. Part IV addresses some of the implementation issues created by this proposal, as well as some of the political realities that this proposal is likely to encounter. Part V concludes with some summary remarks.

\section{Why Is Climate SCIENCE So HaRD?}

While public opinion on the seriousness of climate change has fluctuated, ${ }^{7}$ the general public has consistently harbored fundamental misunderstandings about the causes and risks of climate change ${ }^{8}$ and has maintained an inflated perception of

7. Lydia Saad, Did Hollywood's Glare Heat Up Public Concern About Global Warming?, GALLUP (Mar. 21, 2007), http://www.gallup.com/poll/26932/DidHollywoods-Glare-Heat-Public-Concern-About-Global-Warming.aspx.

8. For example, a recent study found that sixty-seven percent of Americans believe that "reducing toxic waste" would reduce global warming, while fortythree percent believe that "punching holes in the ozone layer with rockets" contributes to global warming. ANTHONY LEISEROWITZ ET AL., YALE PROJECT ON 
the extent of disagreement among climate scientists. ${ }^{9}$ Why is it that global climate change seems to pose such a problem in terms of knowledge dissemination? Hasn't humankind grappled with new and complicated sciences before-like nuclear energy and weaponry, space exploration, and information technology - and eventually wrestled them down to some satisfactory understanding? Why can't people get their heads wrapped around climate change?

Clearly, part of the problem is due to an active campaign waged by a legion of "climate skeptics" 10 of varying credibility who have challenged conventional climate wisdom and scrutinized a broad range of assertions by climate scientists. Some climate skeptics are more serious and thoughtful than others, and some raise more legitimate issues than others. The labels "climate skeptics" and "climate scientists" are not intended to suggest that climate skeptics do not include scientists in their ranks. They include M.I.T. climate science professor Richard Lindzen, an outspoken climate skeptic. ${ }^{11} \mathrm{On}$ occasion, Lindzen has been accused of overselling his climate skepticism, ${ }^{12}$ but for the most part Lindzen's disagreements

Climate Change Commc'n, Americans' Knowledge of Climate Change 1112 (2010), available at http://environment.yale.edu/climate/files/ ClimateChangeKnowledge2010.pdf.

9. See, e.g., Matthew C. Nisbet \& Teresa Myers, Twenty Years of Public Opinion About Global Warming, 71 PUB. OPINION Q. 444, 450-54 (2007); Frank Newport, Americans' Global Warming Concerns Continue to Drop, GalluP (Mar. 11, 2010), http://www.gallup.com/poll/126560/americans-global-warmingconcerns-continue-drop.aspx.

10. "Climate skeptics" is a common term describing people who have doubts about the validity of the science supporting action on climate change. "Skeptic" and "skepticism" are terms that are commonly used by advocates for policy action on climate change. See, e.g., Coby Beck, How to Talk to a Climate Skeptic, GRIST, http://www.grist.org/article/series/skeptics (last visited Apr. 22, 2011); John Cook, How Climate Skeptics Mislead, SkePTICAL SCI. (June 13, 2010), http://www.skepticalscience.com/how-climate-skeptics-mislead.html. The terms are also used by the skeptics themselves. See, e.g., The Climate SCEPTICS, http://climatesceptics.net (last visited Apr. 22, 2011) (subtitled "[t]he world's first political party representing scepticism and objectivity in climate policy"); CLIMATE SKEPTIC, http://www.climate-skeptic.com (last visited Apr. 22, 2011).

11. See, e.g., Richard S. Lindzen, The Climate Science Isn't Settled, WaLL ST. J., Nov. 30, 2009, http://online.wsj.com/article/SB1000142405274870393940457 4567423917025400.html.

12. Lindzen and several other physics professors once wrote an open letter to Congress titled, "To the Congress of the United States: You are being deceived about global warming," and claiming, among many other things, that "there is no such evidence; it doesn't exist.” Letter from Robert H. Austin et al. to the 111th Cong. (July 1, 2009), available at http://www.climatedepot.com/a/1745/ScientistsWrite-Open-Letter-to-Congress-You-Are-Being-Deceived-About-Global-Warming-Earth-has-been-cooling-for-ten-years. This letter was sharply criticized by his 
with climate scientists have been on scientific grounds, mainly having to do with the effect of clouds on climate change. ${ }^{13}$ Skeptics also include Roy Spencer, a respected climatologist at the University of Alabama at Huntsville, who developed a global temperature database based on satellite data. ${ }^{14}$ Scientific progress depends on skepticism, and it would be unprincipled to dismiss the challenges posed by Lindzen and Spencer, at least when they are grounded in science.

Skepticism not grounded in science, however, has also been a part of the climate debate. This less credible skepticism has either been very selective in attacking climate science or taken the form of specious allegations of conspiracy or scientific misconduct. The recent "Climategate" affair, in which a number of emails to and from climate scientists were mysteriously stolen and leaked, has raised the suggestion that climate scientists have engaged in data manipulation. ${ }^{15}$

M.I.T. colleague, Kerry Emanuel, who subsequently blogged on a website for the National Association of Scholars that he "confronted the sole climate scientist among the authors with this statement, and he confessed that he did not hold that to be the case. Last I checked, lying to Congress was a federal crime." Kerry Emanuel, "Climategate": A Different Perspective, NAT'L AsS'N SCHOLARS (July 19, 2010), http://www.nas.org/polArticles.cfm?doc_id=1444.

13. Lindzen has hypothesized that rising temperatures increase the formation of cirrus clouds that would reflect solar radiation. Richard S. Lindzen et al., Does the Earth Have an Adaptive Infrared Iris?, 82 Bull. Am. METEOROLOGICAL Soc'Y 417 (2001). A subsequent study found that the effect of cirrus clouds actually leads to greater warming, not less. Bing Lin et al., The Iris Hypothesis: A Negative or Positive Cloud Feedback?, 15 J. Climate 3 (2002). Lindzen has also hypothesized that increased sea surface temperatures correspond with higher rates of radiation leaving the Earth's atmosphere. Richard S. Lindzen \& YongSang Choi, On the Determination of Climate Feedbacks from ERBE Data, 36 GEOPHYSICAL RES. LETTERS L16705, 6 (2009). This has been criticized for assuming away energy flows in and out of the tropics. Kevin. E. Trenberth et al., Relationships Between Tropical Sea Surface Temperature and Top-of-Atmosphere Radiation, 37 GEOPHYSICAL RES. LETTERS L03702 (2010).

14. Roy W. Spencer \& John R. Christy, Precise Monitoring of Global Temperature Trends from Satellites, 247 SCIENCE 1558, 1558 (1990).

15. Reasonably objective accounts of the controversy are the exception, but one credible account was published by the Guardian (U.K.), not ordinarily known for its restraint. Incorporating public comments, the series seems to have accurately picked out the most salient details. Fred Pearce, Climate Wars, GUARDIAN.CO.UK (Feb. 9, 2010), http://www.guardian.co.uk/environment/series/ climate-wars-hacked-emails. Some fundamental facts seem to account for much of the controversy. The data that were sought by climate skeptics have been presented in a fashion that would appear to be opaque, but the raw data were provided to researchers at the Climatic Research Unit (CRU) at the University of East Anglia, one of the centers of the controversy, on the condition that they not be publicly disseminated. Editorial, Closing the Climategate, 468 NATURE 345, 345 (2010), available at http://www.nature.com/nature/journal/v468/n7322/full/ 468345a.html. 
Although the scientists implicated in Climategate have been exonerated, ${ }^{16}$ doubt seems to persist about the credibility of climate science. ${ }^{17}$ Other forms of skeptical nonsense are more substantive. Some skeptics have asserted that global warming is due to increased sunspot activity, or that Arctic sea ice is actually increasing, ${ }^{18}$ and have mis-cited sources as support for

It remains the case that many of the data used by CRU scientists are covered by agreements that prevent their wider distribution. . . . There are often good reasons for such sequestering of data, and some studies might not be done without it. But where the full information needed to reproduce a study is not publicly available,

Id. scientists have a duty to report that, and say why.

16. See, e.g., Sir MuIR Russell ET Al., The IndePendent Climate Change E-MAILS REVIEW (2010), available at http://www.eenews.net/assets/2010/07/08/ document_cw_01.pdf; Lauren Morello, 'Climategate' Investigators Find No 'Deliberate' Misconduct by Scientists, ClIMATEWIRE (Apr. 15, 2010), http://www.eenews.net/climatewire/2010/04/15/6 (paid subscription).

17. See, e.g., Anthony Leiserowitz et al., Yale Project on Climate CHANGE COMMC'N, GLOBAL WARMING's Six AMERICAS 9 fig.1 (2010), available at http://environment.yale.edu/climate/files/SixAmericasJune2010.pdf (showing that from November 2008 to January 2010 (spanning the "Climategate" incident) those "alarmed" about global warming decreased from $18 \%$ to $10 \%$ and those "dismissive" (not at all concerned about global warming) rose from $7 \%$ to $16 \%$. Those figures rebounded somewhat but remained below 2008 levels, with those alarmed rising back up to $13 \%$ in June 2010 and those dismissive dropping back down to 12\%). See also David R. Baker, 'Climategate' Fallout May Impact Legislation, S.F. CHRON., July 19, 2010, http://www.sfgate.com/cgibin/article.cgi?file=/c/a/2010/07/19/MNNS1EFLDU.DTL; Patrik Jonsson, Climate Scientists Exonerated in 'Climategate' but Public Trust Damaged, CHRISTIAN SCI. MONITOR, July 7, 2010, http://www.csmonitor.com/Environment/2010/0707/ Climate-scientists-exonerated-in-climategate-but-public-trust-damaged.

18. While many people make these arguments, one prominent example is Lord Christopher Monckton, a former advisor to British Prime Minister Margaret Thatcher and policy advisor to a think tank called the Science and Public Policy Institute. Personnel, SCI. \& PUB. POL’Y INST., http://scienceandpublicpolicy.org/ personnel.html (last visited June 29, 2011). Monckton has asserted, among many other things, that sunspot activity was responsible for global warming and that we would begin to get global cooling, Minn. Free Mkt. Inst., Lord Christopher Monckton Speaking in St. Paul, YouTUBE (Oct. 15, 2009), http:// www.youtube.com/watch? $v=$ stij8sUybx0 at 1:07:00, and also that arctic sea ice has actually been increasing over the last thirty years, Protecting Lower-Income Families While Fighting Global Warming: Hearing Before the Subcomm. on Income Sec. \& Family Support of the H. Comm. on Ways \& Means, 111th Cong. 41 (2009) (statement of Lord Christopher Monckton), available at http://www.gpo.gov/fdsys/pkg/CHRG-111hhrg49410/pdf/CHRG-111hhrg49410.pdf. Sunspot activity has been thoroughly debunked as an explanation of global temperature changes. See, e.g., A.D. Erlykin et al., Solar Activity and the Mean Global Temperature, 4 ENVTL. RES. LETTERS 014006, at 4-5 (2009); Mike Lockwood, Solar Change and Climate: An Update in the Light of the Current Exceptional Solar Minimum, 466 Proc. Royal Soc'y A 303, 323 (2010); T. Sloan \& A.W. Wolfendale, Testing the Proposed Causal Link Between Cosmic Rays and Cloud Cover, 3 EnVTL. RES. LeTTERS 024001, at 6 (2008). Monckton's statement 
these assertions. ${ }^{19}$ While spurious claims are relatively easy for scientists to debunk, they are difficult for most others to process. Even spurious claims, some climate skeptics seem to have astutely calculated, muddy otherwise robust conclusions for a lay public with a limited attention span and competing demands for time. An unwitting media industry, conditioned to provide balanced reporting, has given equal time to climate skeptics, credible or not, and has helped to create an exaggerated impression of controversy among reputable climate scientists and experts. ${ }^{20}$

But it is ultimately self-defeating to focus on the role of climate skeptics in trying to explain why people have trouble understanding climate change. Even without an opposition campaign, the task of communicating and addressing climate change is bound to run into trouble. If there was ever a scientific problem that was tailor-made to create public doubt and confusion, it would be global climate change. This Part outlines some of the reasons that climate change is such a difficult problem to study and communicate. They stem from the disparate sources of climate science, the complexity of the science, and the overwhelming temptation for people to resist engagement with the complicated and depressing realities of climate science.

\section{A. Disparateness}

One obstacle to broad comprehension lies in the disparate, far-flung sources of climate science, which make it more difficult for the lay public to collate the information. Climate science probably should have many origins because climate

that sea ice was declining was based on an inaccurate comparison of two carefully selected years, 1980 and 2009. For two of several rebuttals to this absurdity, see John Abraham, Abraham Shows Monckton Wrong on Arctic Sea Ice, SKEPTICAL SCI. (June 2, 2010), http://www.skepticalscience.com/print.php?n=214, and Alden Griffith, Is Arctic Sea Ice 'Just Fine??, SkEPTICAL SCI. (Aug. 18, 2010), http://www.skepticalscience.com/Is_Arctic_Sea_Ice_Just_Fine.html.

19. Lord Monckton, for example, stated that the International Astronomical Union "held a symposium" on solar activity and "concluded" that solar activity was largely responsible for increases in temperature, Minn. Free Mkt. Inst., supra note 18, at 1:07:55, a conclusion that was denied by the President of the International Astronomical Union's Division of Sun and Heliosphere, John Abraham, Monckton Chronicles Part II-Here Comes the Sun?, SKEPTICAL SCI. (June 4, 2010), http://www.skepticalscience.com/print.php?n=216.

20. Maxwell T. Boykoff \& Jules M. Boykoff, Balance as Bias: Global Warming and the US Prestige Press, 14 GLoBal EnVTL. Change 125 (2004). 
science draws on so many different sources of information, every ecosystem in every corner of the world having something to teach us about the effects of climate change and potential feedback effects. Studying climate change thus requires an extremely broad research effort; no single institution could undertake even a fraction of the research required to understand the broad impacts and sources of climate change. Moreover, some systems are so complex that multiple research efforts are required just to study one system or one aspect of climate change.

To take just one example, there are no fewer than five U.S. government-funded institutes that have made it part of their core mission to study or fund the study of climate changes in the polar regions. ${ }^{21}$ And these five entities do not actually perform the bulk of the work; that is mostly left to the hundreds of groups and institutes based in academic institutions worldwide, many of which are funded by these five entities. $^{22}$ But even collectively, all of these groups are, for lack of a better phrase, just the tip of the iceberg.

There is probably considerable overlap in all of this research. But a time-consuming consolidation would clearly be unhelpful. Some of these entities already cooperate. ${ }^{23}$ Each

21. See, e.g., Arctic Climate Research: Overview, NAT'L SCI. Found., http://www.nsf.gov/news/special_reports/arctic/overview.jsp (last updated July 12, 2008); Arctic Research of the Composition of the Troposphere from Aircraft and Satellites, NAT'L AERONAUTICS \& SPACE ADMIN., http://www.nasa.gov/ mission_pages/arctas (last updated Aug. 7, 2008); NASA GODDARD INST. FOR SPACE STUD., http://www.giss.nasa.gov (last visited June 29, 2011); NAT'L ICE CENTER, http://www.natice.noaa.gov (last visited June 29, 2011); NOAA Arctic Research Program, NAT'L OCEANIC \& ATMOSPHERIC ADMIN., http://www.arctic.noaa.gov/arp (last visited June 29, 2011).

22. See, e.g., BYRD POLAR RES. CENTER, OHIO ST. U., http://bprc.osu.edu (last updated June 2, 2011); INT'L ARCTIC RES. CENTER, U. AlASKA FAIRBANKs, http://www.iarc.uaf.edu (last visited July 6, 2011); NAT'L SNOW \& ICE DATA CENTER, http://nsidc.org (last visited July 6, 2011); Nordic Network on Sea-Ice Research, U. HELSINKI, http://www.helsinki.fi/netice (last visited July 6, 2011); Sea Ice Group, U. OTAGO, http://www.physics.otago.ac.nz/research/ice/index.html (last modified Oct. 8, 2008).

23. For example, the National Science Foundation's Office of Polar Programs itself has several divisions, including one focusing on Arctic programs and one focusing on Antarctic programs. The website for the Division of Arctic Sciences states that " $\mathrm{t}]$ he Foundation is one of 12 Federal agencies that sponsor or conduct arctic science, engineering, and related activities. As mandated by the Arctic Research and Policy Act of 1984, Federal interagency research planning is coordinated through the Interagency Arctic Research Policy Committee (IARPC), which is chaired by NSF." About the Division of Arctic Sciences, OFF. POLAR PROGRAMS, NAT'L SCI. FOUND., http://www.nsf.gov/od/opp/arc/about.jsp (last updated Feb. 4, 2010). 
group, institute, or department has a unique perspective on the arctic environment, and each probably has something important to contribute as a stand-alone entity conducting arctic research. For example, the National Ice Center in Suitland, Maryland, has historically served as a navigational resource, collecting data on Arctic and Antarctic ice conditions, and is jointly operated by the U.S. Navy, the Coast Guard, and the National Oceanic and Atmospheric Administration (NOAA). ${ }^{24}$ The day-by-day ice monitoring is a vital information resource that complements, for example, the analytical modeling and forecasting expertise in other agencies. And the diversity of institutions also serves to monitor ice throughout the world, tracking the recession of glaciers in far-flung corners such as the Himalayas, the Rocky Mountains, and southern Chile. A large, diverse crowd of researchers is a good thing.

But how does anyone make sense of the barrage of information from these hundreds of entities? One institution, the United Nations-created Intergovernmental Panel on Climate Change (IPCC), ${ }^{25}$ has become a repository of climate research and a leading interpreter of climate science. Because of this leadership role, it has also served as a lightning rod. A relatively small number of errors in the IPCC's 2000-plus-page 2007 report on the science and policy of climate change ${ }^{26}$ has

24. Mission Statement, NAT'L ICE CENTER, http://www.natice.noaa.gov/ mission.html?bandwidth=low (last visited June 29, 2011).

25. The IPCC is a United Nations-appointed body of over 400 scientists engaged in the science of climate change. It was created and staffed as part of an attempt to develop some science that was as broadly representative as possible of the divergent viewpoints on climate science. INTERGOVERNMENTAL PANEL ON Climate Change, http://www.ipcc.ch (last visited June 29, 2011). Often criticized, the IPCC was awarded the Nobel Peace Prize, along with former U.S. Vice President Al Gore, in 2007. The Nobel Peace Prize 2007, NobELPRIZE.orG, http://nobelprize.org/nobel_prizes/peace/laureates/2007 (last visited Apr. 22, 2011).

26. Intergovernmental Panel on Climate Change, Climate Change 2007: THE PHYSICAL SCIENCE BASIS (Susan Solomon et al. eds., 2007) [hereinafter IPCC FOURTH ASSESSMENT], available at http://www.ipcc.ch/ publications_and_data/publications_ipcc_fourth_assessment_report_wg1_report_ the_physical_science_basis.htm. The IPCC came under fire for making a surprising claim that Himalayan glaciers could melt away by the year 2035, a claim that was based upon a media interview with a glacier scientist in 1999. For a description of the controversy, see Damian Carrington, IPCC Officials Admit Mistake over Melting Himalayan Glaciers, GUARDIAN.CO.UK (Jan. 20, 2010), http://www.guardian.co.uk/environment/2010/jan/20/ipcc-himalayan-glaciers-

mistake. But the controversy over this mistake only seems to underscore the fact that the 2000-plus-page report contained few errors. For a discussion of the relatively few errors in the IPCC report, see Pew's Gulledge Discusses Research 
spurred calls for the dissolution of the IPCC, and not just by climate skeptics. ${ }^{27}$ But even if the IPCC was not (rightly or wrongly) under assault, it only serves as a rough compiler of climate science, only issuing assessment reports every six or seven years. $^{28}$

In the meantime, it is a huge a challenge to keep track of the daily news about climate science developments, even for a dedicated layperson. Even if one is sophisticated and committed enough to subscribe to a news intermediary such as Greenwire, ${ }^{29}$ the daily bombardment of climate research findings is overwhelming. Under these circumstances, it begins to appear rational to delegate some of the information processing to intermediaries, an interpretive vacuum that interest groups of all types have been happy to fill in a selfserving manner.

\section{B. Complexity and Uncertainty}

A second major cause of the climate comprehension problem is the complexity of climate science and the attendant uncertainties of modeling complex systems. Given the severity of these problems, we should probably feel fortunate to have a reasonably definitive projection of global mean temperature increase. The best estimate thus far, generated by the IPCC, is that a doubling of $\mathrm{CO}_{2}$ concentration in the Earth's atmosphere will most likely lead to an increase in global mean temperature of $2^{\circ} \mathrm{C}$ to $4.5^{\circ} \mathrm{C} .^{30}$ But this is a wide range, and within it, a variety of things can happen. At a $2.5^{\circ} \mathrm{C}$ increase, the Prairie Pothole Region of the central United States and Canada, home to the most productive waterfowl habitat in the world, will lose almost forty percent of its seasonal wetlands; at a $4^{\circ} \mathrm{C}$

and Reporting of Climate Science, E\&ETV (Mar. 2, 2010), http://www.eenews.net/ tv/transcript/1122.

27. John M. Broder, Scientists Taking Steps to Defend Work on Climate, N.Y. TIMES, Mar. 3, 2010, at A11, available at http://www.nytimes.com/2010/03/03/ science/earth/03climate.html.

28. Assessment reports have been issued in 1990, 1995, 2001, and 2007. Reports, InTERgOvernmental PANEL ON Climate ChANGe, http://www.ipcc.ch/ publications_and_data/publications_and_data_reports.shtml (last visited June 29, 2011). The next one is due in 2014. Activities, InTERgOVERnMENTAL PANEL ON CLIMATE CHANGE, http://www.ipcc.ch/activities/activities.shtml (last visited June $29,2011)$.

29. GREENWIRE, http://www.greenwire.com (last visited June 29, 2011).

30. IPCC FOURTH ASSESSMENT, supra note 26, at 12. 
increase, the loss would be closer to eighty-five percent. ${ }^{31}$ Given the extraordinary predictions that climate researchers are being asked to make, this example of uncertainty is not unreasonable. But it does not make for easy communication to a mass audience.

Studying climate change is no less than studying how almost every system on Earth reacts to changing concentrations of greenhouse gases and incorporating them into one gigantic model. Climate models, developed for decades now, essentially try to do this. The most sophisticated climate models, "general circulation models" (GCMs), are so dataintensive that they can only be run on the world's most powerful supercomputers. GCMs depict the Earth's atmosphere as a three-dimensional grid consisting of cells that are, at present, roughly 100 kilometers squared by one kilometer high. ${ }^{32}$ Each of the resulting billions of cells is governed by a menu of physical, chemical, and biological equations that describe what happens in each cell, as well as a number of equations that describe energy transfers between cells. ${ }^{33}$ GCMs are validated and calibrated by seeing how well they reproduce past temperatures. Climate scientists have reconstructed historical records of temperatures using tree rings, mountain glaciers, coral reefs, and pollen from lake beds ${ }^{34}$ and have reconstructed historical $\mathrm{CO}_{2}$ concentrations from frozen air bubbles in ice core samples. ${ }^{35}$ Models are then run as if they were operating in the distant past and trying to predict a future (a more recent past) that climate scientists have already reconstructed. ${ }^{36}$ Despite the painstaking validation process, climate scientists have only slightly alleviated concerns about underlying model quality, especially as the historical reconstructions themselves have come under attack. ${ }^{37}$

31. Lisa G. Sorenson et al., Potential Effects of Global Warming on Waterfowl Populations Breeding in the Northern Great Plains, 40 Climatic Change 343, 358 fig.4a (assuming a seven percent increase in precipitation).

32. Michael D. Mastrandrea \& Stephen H. Schneider, Climate Change Science Overview, in Climate ChANGE SCIENCE AND Policy, supra note 1, at 11, 23-24.

33. Id. at 23 .

34. Id. at 12 .

35. Id. at $16-18$.

36. Id. at 25 .

37. Most notably, the "hockey stick" controversy, referring to the hockey stickshaped graph of global temperatures as a function of time, has been a particularly bloody battleground, with some climate skeptics claiming that it is created by academic fraud, and climate scientists rallying around temperature modelers such as the embattled Michael Mann, one of the central figures in the "Climategate" 
Climate modelers readily concede that even the most sophisticated GCMs can only do so much. While the resolution of GCMs is vastly improved from just a decade ago, much can happen within a space 100 kilometers squared by a kilometer high. Clouds, for example, are often smaller than a cell, so GCMs have only crudely modeled the behavior of clouds. ${ }^{38}$ Climate modelers have also struggled to model the impact of aerosols, airborne particles (often pollution) that may reflect sunlight, reducing the amount of solar radiation trapped in the Earth's atmosphere. ${ }^{39}$ Alternatively, they may also absorb sunlight and increase trapped heat. ${ }^{40}$ Climate modelers have also had to improvise in modeling certain non-anthropogenic events that affect climate, like the 1991 eruption of Mount Pinatubo, which spewed enough volcanic ash into the air to slightly cool global mean temperatures for years. ${ }^{41}$ Every time something happens that affects climate, climate modelers have to scramble to figure out if their models can accurately reproduce the temperature changes resulting from the event. Therefore, uncertainties remain large.

Perhaps more importantly, climate modelers concede that GCMs are generally not very good in modeling many feedbacks that, as a result of temperature increases, could either amplify or attenuate a temperature increase. ${ }^{42}$ Cloud formation due to higher temperatures, for example, could potentially reflect sunlight and reduce temperatures ${ }^{43}$ or could trap more heat within the atmosphere and further increase temperatures. ${ }^{44}$ Models are currently inconclusive in predicting which direction clouds will push temperatures. ${ }^{45}$ Models also struggle with projecting the formation of water vapor, which could increase with higher temperatures, ${ }^{46}$ and the emissions of methane, a

affair. See Jonsson, supra note 17. The original hockey-stick analogy stemmed from a graph appearing in a 1998 article in Nature magazine, depicting the recent increase in global mean temperature as the "blade" part of a hockey stick. Michael E. Mann et al., Global Scale Temperature Patterns and Climate Forcing over the Past Six Centuries, 392 NATURE 779, 783 fig.5b (1998).

38. Mastrandrea \& Schneider, supra note 32, at 24-25.

39. Id. at 19 ("[u]nfortunately, the uncertainty in aerosol radiative forcing complicates the assessment of 'climate sensitivity': the amount the Earth's surface warms for a given increase in forcing").

40. Id.

41. Id. at 25 .

42. Id. at $21-23$.

43. Lindzen et al., supra note 13 , at 429.

44. IPCC FOURTH ASSESSMENT, supra note 26, at 635.

45. Id. at 636 .

46. Id. at 593 . 
greenhouse gas twenty-five times more powerful than $\mathrm{CO}_{2}{ }^{47}$ The emission of methane could increase catastrophically as higher temperatures melt the Arctic permafrost that has trapped huge quantities of methane. ${ }^{48}$ That experts still have little idea of how much methane is being emitted ${ }^{49}$ is indicative of the huge uncertainties that confront climate scientists.

Climate science has made enormous advances in the last several decades. But the world's climate scientists, as a group, are tasked with a continuing research assignment unlike anything ever attempted. Uncertainty and complexity are naturally going to be parts of this process, which makes for problematic communications to a lay public that may not relish the complexity or have the patience for uncertainty and might just be looking for a reason not to think about such a depressing subject.

\section{The Benefits of Denial}

A popular explanation of Galileo's conviction of heresy is that the Catholic Church found his advocacy of Copernican astronomy threatening to the Church's Ptolemaic, Earthcentered astronomy. ${ }^{50}$ However, other more contextual versions

47. Mastrandrea \& Schneider, supra note 32 , at 18.

48. Robert Henson, The Rough Guide to Climate Change 86 (2d ed. 2008).

49. Edward A.G. Schuur et al., The Effect of Permafrost Thaw on Old Carbon Release and Net Carbon Exchange from Tundra, 459 NATURE 556, 556 (2009) ("[t]he rate of carbon release from permafrost soils is highly uncertain"); K.M. Walter et al., Methane Bubbling from Siberian Thaw Lakes as a Positive Feedback to Climate Warming, 443 NATURE 71, 71 (2006). As Walter notes:

Large uncertainties in the budget of atmospheric methane, an important greenhouse gas, limit the accuracy of climate change projections. Thaw lakes in North Siberia are known to emit methane, but the magnitude of these emissions remains uncertain because most methane is released through ebullition (bubbling), which is spatially and temporally variable.

Id. (footnotes omitted).

50. Galileo and the Inquisition, GALILEO PROJECT, http://galileo.rice.edu/bio/ narrative_7.html (last visited Nov. 10, 2010). This story finds some support in Biblical passages that, if taken literally, suggest that Earth is stationary and whatever objects that can be observed from the Earth are the moving objects. See Glenn Elert, The Scriptural Basis for a Geocentric Cosmology, E-WoRLD (Apr. 25, 1999), http://hypertextbook.com/eworld/geocentric.shtml. The Earth could be understood to stand still from the following passages: "tremble before him, all earth; yea, the world stands firm, never to be moved," id. (emphasis added by Elert) (quoting 1 Chronicles 16:30) and "[y]ea, the world is established; it shall never be moved," id. (emphasis added by Elert) (quoting Psalms 93:1). The sun could be understood to be moving from the following: 
emphasize the extent to which Ptolemaic astronomy was the conventional wisdom and how Copernican sun-centered astronomy posed a threat to a broad set of social and economic interests outside of the Church. ${ }^{51}$ In this way, Galileo's trial could be seen as more of a failed campaign than an anti-science persecution. ${ }^{52}$

Like Galileo, climate scientists face numerous threats and challenges as they seek to upend the value judgments implicit in a world economy that has equated fossil fuel combustion with economic growth. U.S. Senator James Inhofe, a long-time and vociferous climate skeptic, recently used his office in the Senate Committee on Environment and Public Works to publish its own specious analysis of climate science, culminating with a list of seventeen climate scientists who, in Inhofe's view, have perpetrated a "fraud" on the public. ${ }^{53}$ The

Then spoke Joshua to the Lord in the day when the Lord gave the Amorites over to the men of Israel; and he said in the sight of Israel, "Sun, stand thou still at Gibeon, and thou Moon in the valley of Aijalon." And the sun stood still, and the moon stayed, until the nation took vengeance on their enemies. Is this not written in the Book of Jashar? The sun stayed in the midst of heaven, and did not hasten to go down for about a whole day.

Id. (emphasis added by Elert) (quoting Joshua 10:12-13).

51. Doug Linder, The Trial of Galileo, U. Mo.-KANsAs CitY (2002), http://www.law.umkc.edu/faculty/projects/ftrials/galileo/galileoaccount.html. As Linder points out:

Copernicus' theory was a challenge to the accepted notion contained in the natural philosophy of Aristotle, the astronomy of Ptolemy and the teachings of the Church that the sun and all the stars revolved around a stationary Earth. In the half-century since its publication,

Id. however, Copernicus' theory met mostly with skepticism.

52. See Richard G. Olson, Science And Religion, 1450-1900: From COPERNICUs TO DARWIN 16 (Johns Hopkins Paperbacks 2006) (2004) (arguing that there is little evidence of Church suppression of astronomical inquiry). One economist has even made the argument that it was the league of astronomy professors that persuaded the Church to quash dissent from the Ptolemaic theory, at that time the dominant theory taught in universities. E. RAY CANTERBERY, THE MAKING OF ECONOMICS-VOLUME I: THE FOUNDATION 64 (4th ed. 2003).

53. Minority Staff of S. Comm. On Env'T \& Pub. Works, 111Th Cong., 'Consensus' Exposed: The CRU Controversy 35-37 (2010) [hereinafter CRU CONTROVERSY], available at http://epw.senate.gov/public/index.cfm?FuseAction= Files.View\&FileStore_id=7db3fbd8-f1b4-4fdf-bd15-12b7df1a0b63. The report states that, "[i]n our view, the CRU documents and emails reveal, among other things, unethical and potentially illegal behavior by some of the world's preeminent climate scientists," $i d$. at 1 , lists the federal laws that the scientists may have violated, $i d$. at $30-31$, lists seventeen climate scientists as "key players," $i d$. at 35-37, and says it is "investigating" those scientists for misconduct, $i d$. at 32 . Inhofe has infamously and persistently called global warming a "hoax." See, e.g., Amanda Little, James Inhofe, Senate's Top Skeptic, 
charges have not stuck substantively, but have succeeded in clouding the reports and their authors. ${ }^{54}$ Even the even-keeled Economist called for the resignation of the head of the IPCC, Rajendra Pachauri, ${ }^{55}$ the man who American energy lobbyists and the George W. Bush administration fought hard to install as IPCC president. ${ }^{56}$ Most ominously, some climate scientists have received death threats relating to their climate work, ${ }^{57}$ including the late Stanford climatologist Stephen Schneider, one of the early pioneers of climate science. ${ }^{58}$

Perhaps even more troubling than the fanaticism behind death threats is the indifference with which much of the global public receives climate science. Even as the IPCC issues more definitive and more worrisome findings, the appetite for legislative action on climate change, particularly in the United States, does not seem to reflect the alarm of climate scientists. ${ }^{59}$ With so much at stake, the public reaction even among those that do consider climate change a problem amounts to little more than a shrug. ${ }^{60}$ A popular climate skeptic blog, Climate Audit, posted by retired Canadian mining executive Steve McIntyre, boasts an incredible audience, claiming over three million hits from September 12, 2010, through August 3, 2011. ${ }^{61}$ The large following of McIntyre's blog appears to suggest that there are significant parts of the

Explains His Climate-Hoax Theory, GRIST (Feb. 25, 2010), http://www.grist.org/article/2010-02-25-james-inhofe-senate-top-skeptic-explainsclimate-hoax-theory.

54. Lauren Morello, Panel Criticizes IPCC Leadership but Upholds Science, ClimateWIRE (Sept. 7, 2010), http://www.eenews.net/climatewire/2010/09/07/3 (paid subscription).

55. Climate Controversies: Flawed Scientists, ECONOMIST, July 8, 2010, http://www.economist.com/node/15450615 ("Dr. Pachauri has been a staunch defender of the panel as it is rather than an advocate for reform that would improve it. He is not the man to carry out the changes it badly needs.").

56. Andrew C. Revkin, Dispute Arises over a Push to Change Climate Panel, N.Y. TIMES, Apr. 2, 2002, at A10.

57. See sources cited supra note 3 .

58. Schneider's early works include The Genesis Strategy: Climate and Global Survival (1976) and Global Warming: Are We Entering the Greenhouse Century? (1989).

59. See LEISEROWITZ ET AL., supra note 17, at 9 fig. 1.

60. For example, the Leiserowitz study reported that among those who were "concerned" about global warming, $15 \%$ of respondents reported that they paid "a lot" of attention to global warming, while 53\% said they paid "some" and $31 \%$ said they paid "a little." Id. at 13 tbl.4. Of the same "concerned" group, 29\% said they were "very interested," while $64 \%$ said they were "moderately interested." Id. at 15 tbl.6.

61. Steve McIntyre, ClimATE AUDIT, http://climateaudit.org (last visited Aug. $3,2011)$. 
general public that seem to at least be ready to be talked out of the dangers of climate change. Rational or not, it is a current reality that many people distrust the sources of the scientific predictions about future climate conditions.

Climate scientists should not be any more surprised by the apathy than they are by the violence. If climate scientists are right, then the world faces a stark choice: either undertake fundamental changes in the way that almost every economy operates, imposing substantial costs on almost every country and society in the world, or roll the dice and see what happens with the Earth's climate. Avoiding this question by finding fault with the underlying science provides enormous psychic benefits.

\section{Reform Proposals}

The disparate, complex, and uncertain nature of climate information thus makes it convenient for people to find fault with climate science. Who wants to do the work required to keep pace with climate science, only to face a choice between two depressing realities? ${ }^{62}$ The high costs of trying to avoid climate change, coupled with the scientific complexities and uncertainties, make a compelling case for rational denial.

Some believe that better communications of climate science can help change minds by better explaining the complexities and uncertainties of climate science in a more familiar context. For example, the notion of insurance has sometimes been invoked as a metaphor for reducing greenhouse gas emissions in the present, whereby humanity would spend some money now, akin to insurance premiums, to

62. It has been argued that in a selfish sense, it is rational to avoid the pain of reducing greenhouse gases now, on the grounds that centuries of economic history suggest that the future generations that will have to deal with climate change will be much wealthier than the current one. This argument has been made by Thomas Schelling, Intergenerational Discounting, 23 ENERGY POL'Y 395, 398 (1995) ("I conclude that most of us will want to discount or depreciate heavily the extra consumption provided for (or conserved for) descendants of the current population, because they are likely to be better off . . .."). However, it has been counter-argued that this is a risky approach because there is a small (as far as we currently know) but significant chance that climate change could have such catastrophic consequences that future generations might not be wealthier after all. See, e.g., STERN, supra note 1, at 162-63; see also Thomas Sterner \& U. Martin Persson, An Even Sterner Review: Introducing Relative Prices into the Discounting Debate, 2 REV. ENVTL. ECON. \& POL'Y 61, 62 (2008). 
address the risk of climate change in the future. ${ }^{63}$ A collection of prominent climate and social scientists have called for a nonpartisan climate communications initiative to take on some of the intermediary role of interpretation. ${ }^{64}$ Too much discussion of Climategate and other putative scandals has taken on the air of self-defense, which has detracted from discussion of the underlying issues. The thinking would be that a separate communications body that is less personally involved with the science itself may have more success focusing the discussion on the science rather than the processes that have been impugned by Climategate and climate skeptics.

Other reforms and oversights have been proposed to bolster the credibility of climate science. In the wake of the few but embarrassing errors in the IPCC Fourth Assessment report, the United Nations created an independent panel to review IPCC procedures for transparency and credibility. ${ }^{65}$ The panel concurred with the IPCC's scientific conclusions but was critical of its procedures. ${ }^{66}$ Universities have also investigated claims against their faculty members accused of manipulating data. $^{67}$

Unsurprisingly, none of these measures have mollified critics or climate skeptics. ${ }^{68}$ It would be fanciful to think that this kind of fiat would change anybody's mind. It has been simple for climate skeptics to attack the review panels in much the same way that they have attacked climate science: that the

63. European Comm'n, EU Action Against Climate Change: Leading GLOBAL ACTION TO 2020 AND BEYOND 7 (2008) ("This is a small price to pay to insure ourselves against dangerous levels of climate change."); Martin L. Weitzman, GHG Targets as Insurance Against Catastrophic Climate Damages 2 (Nat'l Bureau of Econ. Research, Working Paper No. 16136, 2010); Stephanie Doster, Leading UA Scholars Say Early Action Is Best "Insurance Policy" Against Climate Change, U. ARIZ. INST. ENV’T (Jan. 12, 2006), http://www.environment.arizona. edu/news/early-action.

64. Thomas E. Bowman et al., Time to Take Action on Climate Communication, 330 SCIENCE 1044 (2010).

65. Members of UN Climate Oversight Panel Announced, UNITED NATIONS Non-Governmental LIAISON SERVICE (May 5, 2010), http://www.unngls.org/spip.php?article2419.

66. Morello, supra note 54.

67. See, e.g., The Pa. State Univ., RA-10 Final Investigation Report Involving DR. Michael E. MANN (2010), available at http:/live.psu.edu/fullimg/ userpics/10026/Final_Investigation_Report.pdf; RUSSELL ET AL., supra note 16.

68. For example, Senator Inhofe and others still plan to investigate the IPCC. CRU CONTROVERSY, supra note 53; see also Lauren Morello, 'Climategate' Inquiry Vindicates Scientists, CLIMATEWIRE (July 8, 2010), http://www.eenews.net/ climatewire/print/2010/07/08/2 (paid subscription). 
outcomes were pre-ordained, and that the climate conspiracy includes those who are asked to provide oversight. ${ }^{69}$ It is hard to escape the conclusion that climate skeptics will never be convinced by institutional adjustments aimed at making climate science more credible and that these skeptics will find fodder in efforts to increase transparency. This Article thus advocates an entirely different path for evaluating climate science and proposes to draw on an institution that is truly independent: the market.

\section{PREDiCtion Markets}

Talk is cheap. Predictions are very cheap. In the public world of climate science, talk and predictions are not only cheap-they are frequently valueless, issued as they are by individuals and organizations with self-serving agendas and on the basis of questionable information. Quality climate science (and reasonable climate skepticism) is mixed with too much ideology, creating an ill broth containing very little informational nutrition.

There is an institution that, while currently suffering through a period of disapproval, is thought to be apolitical and may still be more confidence-inspiring than climate scientists: the market. The recent global financial downturn has called into question the accuracy of market prices as an indicator of value. The rational expectations hypothesis ${ }^{70}$ and the efficient markets hypothesis, ${ }^{71}$ ideological and intellectual beacons for

69. Climate skeptic Steve McIntyre has lambasted a review of the Climategate emails, chaired by Sir Muir Russell, in a number of entries in his Climate Audit blog. See, e.g., Steve McIntyre, "Without Oversight or Challenge," ClIMATE AUDIT (Oct. 26, 2010), http://climateaudit.org/2010/10/26/withoutoversight-or-challenge; Steve McIntyre, UEA "Welcomes” Untrue Muir Russell Findings, CLIMATE AUDIT (Sept. 11, 2010), http://climateaudit.org/2010/09/11/ueawelcomes-untrue-muir-russell-finding; Steve McIntyre, Blatant Misrepresentation by Muir Russell Panel, Climate Audit (July 22, 2010), http://climateaudit.org/2010/07/22/blatant-misrepresentation-by-muir-russellpanel; Steve McIntyre, Muir Russell-What I'll Be Looking for, CLIMATE AUDIT (July 6, 2010), http://climateaudit.org/2010/07/06/muir-russell-what-ill-be-lookingfor ("I don't expect the Muir Russell report to be as much of an insult to the public as the Penn State report or the Oxburgh report-both of which set the bar pretty low.").

70. Robert E. Lucas, Expectations and the Neutrality of Money, 4 J. ECON. THEORY 103 (1972); John F. Muth, Rational Expectations and the Theory of Price Movements, 29 ECONOMETRICA 315 (1961).

71. Eugene F. Fama, Efficient Capital Markets: A Review of Theory and Empirical Work, 25 J. Fin. 383 (1970). 
market enthusiasts, are obviously under attack. ${ }^{72}$ Robert Schiller's 2000 book Irrational Exuberance, ${ }^{73}$ prescient in its understanding of the delirious overvaluations of the dot-com bubble, was published in a second edition in $2005,{ }^{74}$ just in time to drop hints of the real estate asset bubble that sunk world markets in 2009. Combined with the Enron scandal earlier this century, in which accounting tricks were parlayed into artificially inflated share prices, ${ }^{75}$ traumatic market plunges have cast doubt about whether markets are to be trusted at all. Behavioral economists have long studied systemic divergences from rationality, but it seems that the accumulation of market travails has made it fashionable to find not just exceptions to the rational expectations hypothesis and the efficient markets hypothesis, but to declare that they are "dead" and utterly useless as descriptive theories. ${ }^{76}$

This is hyperbole. No reasonable person doubts that markets still largely work. It would be callous to ignore the individual retirement portfolios that have been wrecked by stock market swings, but by and large, investors still entrust the stock market with large chunks of their individual wealth. Every time stock markets have plunged on the heels of a bursting bubble, investors have eventually returned. And bursting bubbles have only spurred calls for regulation; nobody believes that markets inherently do a poor job of allocating capital, at least as compared with the alternatives.

Most importantly for climate science, markets have always been very effective in knitting together disparate pieces of information and transmitting them in the pithy singularity of a price. If well-designed, markets are capable of collecting, filtering, and processing a huge amount of information of varying quality. An illustrative essay by libertarian icon Leonard Read, ${ }^{77}$ I, Pencil, ${ }^{78}$ concerns the genealogy of a pencil.

72. John Quiggin, Rational Manias, OUT OF THE CROOKED Timber (July 19, 2004), http://crookedtimber.org/2004/07/19/rational-manias; David Wighton, Efficient Market Hypothesis Is Dead-For Now, THE Times (Jan. 29, 2009), http://business.timesonline.co.uk/tol/business/columnists/article5607960.ece.

73. ROBERT J. SCHILLER, IRRATIONAL EXUBERANCE (2000).

74. ROBERT J. SCHILLER, IRRATIONAL EXUBERANCE (2d ed. 2005).

75. See, e.g., Frank Partnoy, Infectious Greed: How Deceit and Risk CORRUPTED THE FINANCIAL MARKETS 302-04 (2003).

76. See Wighton, supra note 72 .

77. Read was also the founder of the Foundation for Economic Education. $A$ Tradition of Freedom, FOUND. FOR ECON. EDUC., http://www.fee.org/office/atradition-of-freedom (last visited July 5, 2011). 
The reason that Read devotes an essay to the lowly pencil is that there is such a huge number of economic factors that determine how many pencils are made. At one time, one and a half billion pencils were made every year in factories in San Leandro, California, and the markets that determined their production levels were (and remain) enormously complex. ${ }^{79}$ Even a simple pencil has a huge number of inputs, including the wood from cedar trees and the graphite (then mined in Ceylon) and the clay (then brought into California from Mississippi) used to make the pencil "lead." 80 There are the labor inputs as well: the labor at the mills, the power plants powering the California pencil factories, and the coffee shops frequented by truckers hauling cedar logs from Oregon to California sawmills. ${ }^{81}$ All of these labor and material inputs have competing uses. The point of Read's essay is that all of the countless allocative decisions made during the course of the manufacturing of a pencil are implicitly made by prices, which signify the scarcity of a commodity or worker and the importance of competing uses. Market prices, in communicating scarcity, collect, filter, and process the countless pieces of information that go into an implicit, decentralized allocation of resources.

The ability to buy and sell in different quantities also allows markets to weight information in accordance to its significance and credibility. If a large retailer that sells school supplies such as Staples or Office Depot were to negotiate a contract for pencils, its negotiated prices would likely reflect a great deal of information and research about the competitive price of pencils. Such a contract would thus likely be both an important (due to the market size of the retailer) and a credible (due to the likelihood that it negotiated a realistic price) source of information.

As Michael Abramowicz explains in his book Predictocracy: Market Mechanisms for Public and Private Decision Making, ${ }^{82}$ markets can also be harnessed to provide non-financial

78. Leonard Read, I, Pencil: My Family Tree as Told to Leonard Read, LIBR. ECON. \& LIBERTY (Dec. 1958), http://www.econlib.org/library/Essays/rdPncl1.html.

79. $I d$.

80. Id.

81. Id.

82. Michael ABramowicz, Predictocracy: MARKet Mechanisms FoR PUblic AND PRIVATE DECISION MAKING (2007). For another review of prediction markets, see Justin Wolfers \& Eric Zitzewitz, Prediction Markets, 18 J. ECON. PERSPECTIVES 107 (2004). 
information to improve public decision-making. A prediction market is a constructed market in which trades are made on contracts that specify payouts based on specific outcomes. Participating in a prediction market is betting on outcomes. Depending on the type of prediction market, "shares" of an outcome are bought and sold so that the trading prices reflect expectations about the likelihood of that specific outcome ultimately taking place. As briefly noted above, perhaps the best known of the examples of prediction markets are housed at the Iowa Electronic Markets project, ${ }^{83}$ which for decades has accurately predicted, among other things, political election outcomes. In the Iowa Electronic Markets project, trading in presidential prediction markets can take place on a "winnertake-all" basis, which involves only binary outcomes (Republican or Democrat winning the Presidency) in which the traded contracts pay out the full amount if the outcome occurs and nothing if it doesn't. Thus, an "Obama share" after the 2008 presidential election was worth the full payout amount, and a "McCain share" was worth nothing. Alternatively, trading can take place on a "share" basis, in which the specified payout is indexed to a continuous number, such as the popular vote share, so that an Obama share was worth fifty-three cents on the dollar after the election, while a McCain share was worth forty-seven cents on the dollar. ${ }^{84}$ Either way, trade prices leading up to elections reflect broad expectations about the outcome. As Abramowicz has argued, prediction markets are best justified by the fact that in a prediction market, "traders can profit from information suggesting that the market price is wrong." 85 In this way, prediction markets harness disparate pieces of information and aggregate them into the price.

The Iowa Electronic Markets project-which has operated to predict a wide variety of outcomes, including many political elections (not just presidential)-has generally been more accurate than polls, and considerably less volatile. ${ }^{86}$ The reason

83. IEM PROJECT, supra note 6.

84. Popular Vote in the 2008 Presidential Election, HistoryCEnTRAL.COM, http://www.historycentral.com/elections/12008/popularvote2008.html (last visited Dec. 7, 2010).

85. ABRAMOWICZ, supra note 82, at 15.

86. See, e.g., JAMES SurowiECKI, THE Wisdom of CROWDS 17-19 (2004); Joyce Berg et al., Results from a Dozen Years of Election Futures Markets Research, in HANDBOOK OF EXPERIMENTAL ECONOMICS RESULTS 742, 748 (Charles R. Plott \& Vernon L. Smith eds., 2008); Joyce E. Berg, Forrest D. Nelson 
for this is that a prediction market like the Iowa Electronic Markets project seems to do a better job of evaluating the value of new information. ${ }^{87}$ For example, while a poll errantly captures the emotional "bump" after, say, a party's nominating convention, a prediction market is likely to have factored into its price the ultimate value of such an anticipated event. ${ }^{88}$ Prediction markets generally do not get excited and overreact.

But Abramowicz argues that much more information could be mined for a variety of other purposes. Hewlett-Packard and Eli Lilly, huge companies with critical decisions to make about product lines, have set up internal (i.e., employee) prediction markets to predict future printer sales (in the case of HP) and future pharmaceutical sales (in the case of Eli Lilly). ${ }^{89}$ They were remarkably effective in identifying which products were likely to succeed in the marketplace. ${ }^{90}$ Most relevant for purposes of this Article, prediction markets can be used to help formulate public policy. Among the public policy applications for prediction markets that Abramowicz calls for are prediction markets for defense and anti-terrorism policy, ${ }^{91}$ fiscal policy, ${ }^{92}$ banking regulation, ${ }^{93}$ and mine safety regulation. ${ }^{94}$ In all of these cases, Abramowicz argues, prediction markets have advantages over more traditional policymaking processes because of the potential for the markets to harness information from disaggregated and informed market participants. ${ }^{95}$

Abramowicz's suggestion of using prediction markets to predict the number of injuries and deaths at particular mines seems especially prescient in light of the 2010 explosion of a Massey Energy-operated Upper Big Branch mine in West Virginia that killed twenty-nine miners, the worst mine explosion in the United States since $1970 .^{96}$ During the

\footnotetext{
\& Thomas A. Rietz, Prediction Market Accuracy in the Long Run, 24 InT'L. J. FORECASTING 285 (2008).

87. Oleg Bondarenko \& Peter Bossaerts, Expectations and Learning in Iowa, 24 J. BANKING \& Fin. 1535, 1547-48 (2000).

88. Berg, Nelson \& Rietz, supra note 86, at 293.

89. SUROWIECKI, supra note 86, at 221.

90. Id.

91. ABRAMOWICZ, supra note 82, at 46-49.

92. Id. at $62-63$.

93. Id. at $148-49$.

94. Id. at 151.

95. Id. at 282 .

96. Greg Bluestein \& Vicki Smith, Mine Rescue Effort Turns to Recovery, MSNBC.COM (Apr. 10, 2010), http://www.msnbc.msn.com/id/36183425/ ns/us_news-life.
} 
ensuing investigation, Massey Energy disputed accounts of the Mining Safety and Health Administration officials who cited past violations and illegally high levels of coal dust in the mine at the time of the explosion as causes of the explosion. ${ }^{97}$ While prediction markets in these kinds of tragic events have been condemned as "people profiting from terrible things happening," 98 it is worth wondering about the following proposition: Might a prediction market in safety violations (or even injuries) at specific mines-a market that could have drawn in mining experts with important local knowledge about the Upper Big Branch mine-have saved the lives of the 29 miners killed in the Massey explosion?

In appreciating the vast information network embodied in market prices, it becomes apparent how markets can play a role in aggregating and weighting the disparate pieces of climate science. This Article proposes to set up a prediction market for future climate outcomes by linking a carbon tax to climate outcomes and then establishing a market for tradable permits to emit $\mathrm{CO}_{2}$; these permits would be unitary exemptions from the carbon tax. If greenhouse gas emitters needed information about future climate conditions-as they would under this proposal in order to evaluate their potential future carbon tax liabilities-they would become effective collectors of climate information. Together with other emitters that face a potential carbon tax liability, they would likely form a network of gatherers of climate information. While many amateur climate wonks would continue to pore through reams of daily climate reports, the evaluations of emitting firms would likely take on central importance.

In addition, prediction markets, like markets generally, weight the value of information by allowing market participants to vary the amount of money invested. This allows prediction market participants to place a premium on information that they believe to be especially important or credible and likely to change the expectation of an outcome. This kind of weighting is difficult with an opinion poll. Even

97. Kimberly Kindy, Probe into Fatal W.V. Mine Explosion Finds Large Amounts of Volatile Coal Dust, WASH. Post, Sept. 17, 2010, http://www.washingtonpost.com/wp-dyn/content/article/2010/09/17/ AR2010091704242.html.

98. SUROWIECKI, supra note 86 , at 80 ; see also ABRAMOWICZ, supra note 82 , at 47 (both discussing political criticism of prediction markets that would have allowed trading in events in the Middle East including-but not limited toterrorist attacks). 
surveys that provide a rating scale are vulnerable to variations in how different people express their opinions.

Perhaps most importantly, a prediction market in future climate conditions would force market participants-in the first instance, emitters of greenhouse gases that face a future carbon tax liability-to be extremely discerning consumers of climate science, critically evaluating climate science and the critiques offered by climate skeptics. While some emitters may have an ideological axe to grind in terms of climate policy, it would turn out to be very expensive to allow an ideological filter to affect their valuations of different pieces of climate science. For example, one study showed that while the majority of participants in a prediction market for the 1988 presidential election were Republican, the predicted outcome was not ideologically skewed toward a Republican result but accurately predicted the margin of victory by President George H.W. Bush over Michael Dukakis in 1988. ${ }^{99}$ Talk is cheap, but prediction markets force participants to back their stated beliefs with money, forcing a person to, as Abramowicz puts it, "put] his money where his mouth is." climate scientists and climate skeptics alike can, instead of lobbing rhetorical grenades at the other, profit by trading on what they believe is superior information. It would not be Pollyannaish to imagine that some of the vitriol characterizing climate debate could be displaced by a discussion of whether the market price for future emissions permits is too high or too low. Complaints that the market price reflects too much optimism or too much pessimism about future climate outcomes could be met with the advice to go buy or sell some emissions permits.

\section{THE TAX-AND-CAP-AND-TRADE PROPOSAL}

The proposal in this Article builds upon two other works. First, Professor Abramowicz's Predictocracy features prominently and obviously in this proposal and its policy justifications. Second, economist Ross McKitrick has proposed

99. Robert Forsythe et al., Anatomy of an Experimental Political Stock Market, 82 AM. ECON. REV. 1142, 1155-56 (1992).

100. ABRAMOWICZ, supra note 82 , at 8 . 
an important precursor to this proposal: a temperature-indexed carbon tax. ${ }^{101}$

McKitrick proposed the idea of a temperature-indexed carbon tax in part as a way of introducing a different "referee" for climate science. ${ }^{102}$ If temperatures increase, the level of the carbon tax goes up. ${ }^{103}$ As McKitrick, a climate skeptic, told New York Times columnist John Tierney:

The only people who lose will be those whose positions were disingenuous, such as opponents of greenhouse policy who claim to be skeptical while privately believing greenhouse warming is a crisis, or proponents of greenhouse gas emission cuts who neither understand nor believe the I.P.C.C. projections, but invoke them as a convenient argument on behalf of policies they want on other grounds even if global warming turns out to be untrue. ${ }^{104}$

McKitrick's clever (and admirably constructive) proposal should be received with several caveats. First, a temperatureindexed carbon tax should not be viewed as a way of neatly internalizing the cost of $\mathrm{CO}_{2}$ emissions. I have argued in my other work ${ }^{105}$ that a carbon tax is an imperfect, though a first and necessary, step toward creating an effective carbon price. Given the current vast and profound disagreements over the appropriate price of carbon, ${ }^{106}$ however, it seems unrealistic to believe that any one-to-one correspondence between damages and contemporaneous temperature measurements could be agreed upon. This caveat is not specific, of course, to McKitrick's proposal.

Second, McKitrick's model limits the degree to which temperature could be a nonlinear function of emissions. ${ }^{107}$ This

101. See Ross McKitrick, A Simple State-Contingent Pricing Rule for Complex Intertemporal Externalities, 33 ENERGY ECON. 111 (2011). The implementation of a temperature-indexed carbon tax would be based upon the impartial, nonmanipulable reporting of an increase in tropical temperatures.

102. John Tierney, Trusting Nature as the Climate Referee, N.Y. TIMES, Dec. 15,2009 , at D1.

103. McKitrick, supra note 101, at 111.

104. Tierney, supra note 102.

105. Shi-Ling Hsu, The Case for a Carbon TaX: Getting Past Our HangUPS to EFFeCtive Climate Policy (2011).

106. See infra Part IV.A.2.

107. McKitrick, supra note 101, at 113. McKitrick's model also imposes an assumption of symmetry, which requires that a lagged marginal effect of emissions on temperature be the same no matter what the year. In other words, while temperature may be more influenced by some years than others, the 
is problematic, since it is widely believed among climate scientists that nonlinearities may exist in a relationship between emissions and temperature because of a number of potential tipping points, or "thresholds," that may exist beyond which some runaway positive feedbacks could suddenly change the state of the Earth's climate. ${ }^{108}$ It seems problematic to assume that even in short periods of time, the relationship between temperature and emissions could not change quickly.

The final caveat to McKitrick's proposal pertains to his temperature index, which he proposes should be a mean annual temperature for the tropical troposphere (the upper atmospheric layers above the band of Earth between twenty degrees north and south of the Equator). ${ }^{109}$ McKitrick offers a reasonable argument that instead of the more intuitive global mean temperature, tropical tropospheric temperature offers better data and a more stable signal. ${ }^{110}$ But while this might serve as a reasonable climate "referee," it would not necessarily be a good barometer of the state of the Earth's climate, statically or over a long period of time. A single tropical temperature reading would obscure, among other things, an increase in extremes that could cancel each out when averaged.

Expanding on this last caveat, this Article proposes a more general policy of indexing a carbon tax to not just one temperature but a broader set of non-manipulable climate outcomes. A broader "basket" of climate outcomes, not unlike a consumer price index, might be devised to be a better indicator of the state of the Earth's climate. The effects of climate change on humankind are not necessarily limited to a change in the global mean temperature, though that change in itself is likely a very good proxy for many indirectly harmful effects on humankind, such as those affecting sensitive species and ecosystems. But in thinking about what is directly and immediately worrisome about climate change, a number of

influence of emissions on temperature ten years (for example) hence will always be the same, no matter the year. $I d$.

108. See, e.g., Martin L. Weitzman, On Modeling and Interpreting the Economics of Catastrophic Climate Change, 91 REV. ECON. \& STAT. 1, 13 (2009) (citing and analyzing Margaret S. Torn \& John Harte, Missing Feedbacks, Asymmetric Uncertainties, and the Underestimation of Future Warming, 33 GeOPHYSICAL Res. LeTTERs L10703 (2006)); see also H. Damon Matthews \& David W. Keith, Carbon-Cycle Feedbacks Increase the Likelihood of a Warmer Future, 34 GEOPHYSICAL RES. LETTERS L09702, 1 (2007).

109. McKitrick, supra note 101, at 117-18.

110. See id. 
other climatic effects leap to mind: (1) temperature extremes, so that there will be more extremely hot days that could prove fatal to vulnerable populations and result in forest dieback ${ }^{111}$ and forest fires; (2) the possibility of more intense hurricanes and tropical storms; (3) the intensification of hydrological cycles, with the dual results that precipitation would become more intense (and less manageable, leading to more flooding and less water storage capability) and droughts would last longer and be more severe; (4) sea level rises; and (5) ocean acidification. All of these effects are thought to be (though not uncontroversially) among the potential and anticipated effects of climate change, and absent a successful geo-engineering effort $^{112}$ they are outcomes that are non-manipulable. All of these effects are directly relatable to significant damages, though adaptation efforts ${ }^{113}$ may alleviate some of the damages. For example, developed countries such as the United States could clearly do a better job of protecting their most vulnerable populations from heat waves. All of these climatic events are monitored internationally, routinely, and reliably so that even in remote parts of the planet weather anomalies are susceptible to measurement and counting. ${ }^{114}$ Some details on

111. Forest "dieback" is the term for unnatural tree mortality due to environmental stress. See Oliver L. Phillips et al., Drought Sensitivity of the Amazon Rainforest, 323 SCIENCE 1344, 1344 (2009).

112. "Geo-engineering" is a general term used to describe a wide variety of measures aimed at reducing the atmospheric concentration of greenhouse gases, post-combustion or post-release, sometimes by directly removing greenhouse gases from the atmosphere or reducing the amount of solar radiation that reaches the Earth. For example, one frequently debated idea involves the promotion of ocean algal growth, or "ocean fertilization," which would promote the absorption of $\mathrm{CO}_{2}$ but would also have numerous side-effects for ocean biology and chemistry. Global Envtl. Alert Serv., Geoengineering to Combat Global Warming, UNITED NATIONS ENV'T PROGRAMME (May 2011), http://na.unep.net/geas/newsletter/May_ 11.html. A much more innocuous form of geo-engineering involves painting roofs white to reflect sunlight. Id. For a general discussion of geo-engineering, see HENSON, supra note 48, at 330. This article discusses geo-engineering infra Part IV.E.

113. "Adaptation" is a general term used to describe all forms of adjustment to a climate-changed world that societies may undertake, now and in the future. See HENSON, supra note 48, at 299. For example, building sea walls is a way of adapting to higher sea levels and has been frequently discussed as a way of protecting New York City from sea level rises. Launch a Citywide Strategic Planning Process for Climate Change Adaptation, PLANYC 2030, http://prtl-prdweb.nyc.gov/html/

planyc2030/html/plan/climate_citywide.shtml (last visited July 6, 2011).

114. See, e.g., GISS Surface Temperature Analysis, GODDARD Inst. FOR SPACE STUD., NAT'L AERONAUTICS \& SPACE ADMIN., http://data.giss.nasa.gov/ gistemp/graphs (last modified July 15, 2011) (monitoring global temperatures); 
exactly how this index would be constructed are discussed in Part IV, infra.

But there is even more that can be done with the idea of an indexed carbon tax. There is no reason to limit the amount of information created by market transactions to contemporaneous climate conditions. Because current emissions will contribute to higher future temperatures for centuries, ${ }^{115}$ it is important to obtain and evaluate-right now-climate science about future conditions. Professor McKitrick's indexed carbon tax would do this, but the signal would not be very clear. A temperature-indexed carbon tax, provided that a government is sufficiently committed to maintaining it for a long period of time, would induce emitters to plan for the future and undertake capital investments that reflect their expectations about what the future temperature will be. When the American Electric Power Company (AEP), the largest $\mathrm{CO}_{2}$ emitter in the world, ${ }^{116}$ invests in renewable energy sources such as wind farms, there could well be a reasonable inference that it anticipates a higher temperature in the future. But the signal would be muddled. AEP has, in fact, been investing heavily in renewable energy sources and

Global Historical Climatology Network Gridded Products, NAT'L Climatic DATA CENTER, NAT'L OCEANIC \& ATMOSPHERIC ADMIN., http://lwf.ncdc.noaa.gov/tempand-precip/ghcn-gridded-prcp.html (last updated May 16, 2011) (mapping temperature and precipitation anomalies); Hurricane/Tropical Data, UNISYs, http://weather.unisys.com/hurricane (last visited Sept. 26, 2010) (providing data on hurricanes and tropical storms); Integrated SST Data Products, GROUP FOR High-Resol. SEA SuRface TeMPeRATURE, http://www.ghrsst.org (last visited Sept. 26, 2010) (providing products to monitor sea surface temperature); INT'L Satellite Cloud Climatology ProjeCt, http://isccp.giss.nasa.gov/index.html (last visited Sept. 26, 2010) (featuring data on clouds); Overview of WCRP Climate Extremes Research, Climate VARIABILITY \& PREDICTABILITY, http://www.clivar.org/organization/extremes/extremes.php (last updated Nov. 11, 2010) (providing data on ocean surface and upper ocean thermal temperatures and global wind data); State of the Climate: Global Hazards-August 2010, NAT'L Climatic Data Center, NAT'L OCEanic \& Atmospheric Admin. (Sept. 2010), http://www.ncdc.noaa.gov/sotc/hazards/2010/8 (featuring rainfall and flooding data, drought, and extreme weather events).

115. Carbon dioxide has had a residence in the Earth's atmosphere for hundreds of years, meaning that emissions of $\mathrm{CO}_{2}$ now will form part of the Earth's stock of greenhouse gases for millennia, unless that $\mathrm{CO}_{2}$ is removed somehow. See IPCC FouRTH ASSESSMENT, supra note 26, at 125-26.

116. This conclusion is derived from running a query on an Excel spreadsheet that is downloadable from the website of the U.S. Environmental Protection Agency's “eGRID” project. Clean Energy, U.S. EnVTL. ProteCTION AGEnCY, http://www.epa.gov/cleanenergy/egrid (click on "eGRID2007 year 2005 plant and aggregation files (ZIP)” to download spreadsheet) (last visited Dec. 13, 2010). 
carbon capture and storage technology. ${ }^{117}$ But the primary reason for AEP's move towards renewable energies is almost certainly to begin to prepare a behemoth company for a future regulatory environment that will price $\mathrm{CO}_{2}$ emissions. Teasing out the impact of an indexed carbon tax from AEP's other strategic decisions would be difficult. Thus, something over and above the observation of capital investments made putatively in anticipation of a future tax liability is needed.

There is thus a second part to this proposal: a cap-andtrade program for permits to emit a ton of $\mathrm{CO}_{2}$ in future years, the exercise of which would displace the carbon tax liability for emitting one ton of $\mathrm{CO}_{2}$. Under this second part of the proposal, a batch of permits for each of many future years ${ }^{118}$ will be auctioned off every year. Once auctioned, the permits would be tradable until, of course, they are exercised in the year of their designated vintage. Permits can be redeemed by whoever is subject to the carbon tax, but trading can take place among any interested parties. Emissions permit-trading is now a familiar part of environmental law, having formed the basis of the 1990 Clean Air Act Amendments and its pioneering cap-and-trade program for permits to emit sulfur dioxide. ${ }^{119}$ Until recently, when the failure of the U.S. Congress to pass climate legislation torpedoed any potential for carbon credit trading, carbon credits were traded on the Chicago Climate Exchange. ${ }^{120}$ The motivation for this part of the proposal is to tie market activity in tradable permits to future climate outcomes and thereby create a market for information about future climate outcomes. If emitters with future carbon tax liability are rational and risk-neutral, they should be willing to pay for tradable permits a price just slightly less than their anticipated liability under the indexed carbon tax.

This second part of the proposal induces emitters to forecast their own future carbon tax liabilities and reveal their

117. AEP Doubles Renewable Energy Goal to 2,000 MW, RENEWABLE ENERGY WORLD (Apr. 29, 2009), http://www.renewableenergyworld.com/rea/news/article/ 2009/04/aep-doubles-renewable-energy-goal-to-2000-mw.

118. The issue of how many years in advance permits will be available is discussed infra Part IV.B.2.

119. Clean Air Act, 42 U.S.C. $\$ \S 7401-7671$ (1994).

120. Markets, ChI. Climate ExChange, https://www.theice.com/ccx.jhtml (last visited July 6, 2011). Carbon trading has been suspended in light of the failure of the United States to pass cap-and-trade legislation, or any climate policy at all for that matter. Dwindling Interest to Shutter Chicago Climate Exchange, GREENWIRE (Nov. 17, 2010), http://www.eenews.net/Greenwire/print/2010/11/17/8 (paid subscription). 
forecasts through the exchange of tradable permits. Such private forecasts are not oracles, of course. But the level of private concern over future climate conditions, as expressed through market prices for permits, is at least an unbiased opinion derived from self-interest. The price bid by emitters for, say, permits to emit in 2020 would speak volumes about private expectations of the consequences of climate change. Moreover, this information would be free of suspicions of conspiracies by climate scientists to shore up their research grant fiefdoms ${ }^{121}$ or desires by radical environmentalists who really wish to use climate change as an excuse for imposing environmental restrictions. ${ }^{122}$ The market price is a far stronger and clearer signal of future expectations than what would probably be mostly anecdotal information concerning which firms are worried about and planning for rising temperature taxes.

There is one final benefit of this tax-and-cap-and-trade proposal that is worth emphasizing, as it achieves something unprecedented in both enhancing climate science and accomplishing something far more effectively than any previous prediction market has accomplished. This proposal would create a private market for information and information processing about climate outcomes. Clearly, emitters with future carbon tax liabilities do not have, and would be unlikely to develop, the internal capacity to do their own climate outcome projections. At the same time, a carbon tax liability that is tied to future climate outcomes would compel most emitters to invest some money to investigate the likely extent of their liabilities. This could constitute a major source of funding for a new climate information market.

Those with direct and first-hand information about climate science-mostly climate scientists, but other highly interested climate change wonks as well-would likely buy and sell permits, aggregating information in an important manner along the way. But by and large, the most important traders in a market for permits issued under this proposal will be those $\mathrm{CO}_{2}$ emitters, such as AEP, that may have to rely on the

121. See Roy W. Spencer, On the House Vote to Defund the IPCC, RoY SPENCER, PH. D. (Feb. 19, 2011), http://www.drroyspencer.com/2011/02/on-thehouse-vote-to-defund-the-ipcc ("The perpetual supply of climate change research money also biases them. Everyone in my business knows that as long as manmade climate change remains a serious threat, the money will continue to flow, and climate programs will continue to grow.").

122. See supra text accompanying note 104. 
permits for their future compliance with a carbon tax scheme. In 2005, AEP emitted approximately 161 million tons of $\mathrm{CO}_{2}{ }^{123}$ if one assumed a very modest carbon tax that was set to five dollars per ton at current climate outcomes, ${ }^{124}$ AEP's annual carbon tax liability would be about $\$ 805$ million. If climate outcomes increased by, say, twenty-five percent, its annual carbon tax liability would top one billion dollars. All 101 electricity generators in the EPA's eGRID database would have a combined current carbon tax liability (assuming a rate of five dollars per ton of $\mathrm{CO}_{2}{ }^{125}$ ) of $\$ 8.75$ billion. ${ }^{126}$

Because of the amounts of money involved, it is the participation of large emitters in a cap-and-trade program for emissions futures that is likely to make or break the credibility of climate science. In essence, this proposal uses markets to turn the evaluation of climate science over to those emitters that will potentially rely on those permits for their emitting operations. Environmental advocates may chafe at the notion that the greatest greenhouse gas emitters will have such a large say in evaluating the quality of climate science, but $\$ 8.75$ billion is a lot of impetus for honestly evaluating climate science. As for the prickly personalities that debate climate science, Professor McKitrick and other climate skeptics would no doubt be pleased that those guilty of deceit or of shoddy climate science would be punished by being ignored.

\section{IMPLEMENTATION ISSUES AND THE REALPOLITIK OF CARBON TAXES}

As is the case with all legal policy, the devil is in the details. Whether this proposal succeeds in lending clarity and cohesiveness to climate science, and whether it succeeds in generating new climate information, depends vitally on how it is carried out. This Article does not set out to produce a finished, policy-ready proposal, so some details are left to future work. But some principles and considerations are set out here to guide future development and implementation of this proposal. Sections A and B in this Part set out the key

\footnotetext{
123. Clean Energy, supra note 116.

124. See infra Part IV.A.2 for discussion of setting the tax.

125. eGRID also measures methane emissions, which could provide a means for expanding the carbon tax to include methane emissions. Clean Energy, supra note 116.

126. Id.
} 
parameters in setting up the indexed carbon tax and the capand-trade program, respectively. This includes a critical discussion of the climate outcomes that would be made a part of the index, leaving some of the details for the Appendix. Sections C through E address critical questions that pertain to the effectiveness of this program. In closing out this Part, Section F addresses some of the political obstacles faced by this proposal.

\section{A. Establishing the Carbon Tax}

Implementing a carbon tax is, as I have argued in my other work, generally easier than setting up a cap-and-trade program. ${ }^{127}$ Two fundamental questions, however, must be answered: Who will be subject to the tax, and how should the tax level be set? This proposal, as well, must answer a third critical question: What climate outcomes should be included in the index that determines the level of the carbon tax? This Section addresses these questions.

\section{Who Is Subject to the Tax?}

A carbon tax is a liability based upon the quantity of $\mathrm{CO}_{2}$ emitted, generally as a tax per ton of $\mathrm{CO}_{2}$ emitted. The carbon tax would be levied at some point along the chain of distribution of fossil fuels, the main fossil fuels being coal, natural gas, and petroleum, which account for nearly eighty percent of all greenhouse gas emissions in the U.S. ${ }^{128}$ Where should the carbon tax be levied? There are a number of options. The cleanest option is to require permits far upstream, where (1) coal is mined, (2) natural gas is processed, (3) petroleum is refined, and (4) each of these fossil fuels is imported. ${ }^{129}$ By imposing the tax upstream, comprehensive regulation can be achieved by taxing (or requiring permits of) a relatively small

127. HsU, supra note 105 , at $87-88$.

128. U.S. EnVtl. Prot. Agency, Inventory of U.S. Greenhouse Gas EMISSIONS AND SINKS: 1990-2009, at ES-4 to ES-6 tbl.ES-2 (2011) [hereinafter GREENHOUSE GAS EMISSIONS], available at http://www.epa.gov/climatechange/ emissions/downloads11/US-GHG-Inventory-2011-Complete_Report.pdf

(illustrating that of 6633.2 million metric tons of emissions, 5209.0 come from fossil fuel combustion).

129. This proposal was most recently made by Gilbert E. Metcalf \& David Weisbach, The Design of a Carbon Tax, 33 HARV. ENVTL. L. REV. 499, 501 (2009). 
number of entities in the United States ${ }^{130}$ : 148 petroleum refineries, ${ }^{131} 1,407$ coal mines, ${ }^{132} 530$ natural gas processors, ${ }^{133}$ and points of importation. Fortunately, as an economic matter, absent transaction and enforcement costs, the economic effects of an upstream carbon tax (or cap-and-trade program) can be demonstrated to be the same as a similarly comprehensive downstream carbon tax (or cap-and-trade program), where the price is levied on the end user. ${ }^{134}$ For heavily regulated and efficiently traded energy commodities, tax burdens are passed up and down the chain of distribution with little friction. Moreover, the administrative costs are considerably less for upstream programs. ${ }^{135}$ Pulling Canadian entities into this program would be a sensible extension for a country with a closely integrated energy infrastructure that is accustomed to being a climate change policy-taker anyway. ${ }^{136}$

A carbon tax could also, likely without much trouble and administrative expense, be expanded to include a number of other $\mathrm{CO}_{2}$-emitting activities and other heat-trapping greenhouse gases. ${ }^{137}$ It turns out, for example, that "fugitive emissions" of $\mathrm{CO}_{2}$ from the cement-making process, those related to the chemical process used to grind up raw materials into cement, can be estimated with reasonable accuracy from

130. Originally estimated by Metcalf \& Weisbach, id. at 501, a change in the number of refineries, coal mines, and natural gas processors does not materially change this estimate.

131. U.S. ENERgy INFo. AdMin., REFInERY CAPACITY REPORT 1 tbl.1 (2011), available at http://www.eia.gov/petroleum/refinerycapacity/refcap11.pdf.

132. U.S. ENERgy Info. AdMin., ANNUAL COAL REPORT: 2009 at 13 tbl.1 (2010), available at http://www.eia.gov/cneaf/coal/page/acr/acr.pdf.

133. U.S. Energy Info. AdMin., NATURAL Gas Processing: The Crucial Link Between Natural Gas Production and Its Transportation to MaRket 6 tbl.1 (2006), available at http://www.eia.gov/pub/oil_gas/natural_gas/ feature_articles/2006/ngprocess/ngprocess.pdf.

134. See, e.g., Metcalf \& Weisbach, supra note 129, at 523 ("[T] tax and its efficiency effects are unrelated to the statutory obligation to remit the tax. This means that, in deciding where to impose the tax (choosing the remitting entity), one can focus on minimizing collection and monitoring costs while ensuring maximum coverage.”).

135. Erin T. Mansur, Upstream Versus Downstream Implementation of Climate Policy 3 (Nat'l Bureau of Econ. Research, Working Paper No. 16116, 2010), available at http://ssrn.com/abstract $=1626605$.

136. Recently, Environment Canada announced that it would follow the United States in promulgating a set of greenhouse gas emissions regulations that the United States was implementing pursuant to its Clean Air Act. Canada Might Follow U.S. EPA's Lead on Permitting-Environment Minister, GREENWIRE (Nov. 29, 2010), http://www.eenews.net/Greenwire/print/2010/11/29/8 (paid subscription).

137. Metcalf \& Weisbach, supra note 129 , at 537. 
the amount of lime used in the industrial process. ${ }^{138}$ Similarly, regulating emissions from landfills by requiring the monitoring and measurement of emissions of methane, a greenhouse gas twenty-five times more powerful than $\mathrm{CO}_{2}$, is thought to be a manageable administrative task. ${ }^{139}$ Imposing a carbon tax on cement manufacturers for fugitive emissions and to landfill operators for methane emissions would thus appear to be reasonable extensions. This proposal can thus be expanded to cover a number of other greenhouse gas-emitting activities.

\section{The Carbon Tax Level}

A carbon tax, as noted above, is a tax levied on a per-ton basis. But how much of a tax should be levied on a ton of $\mathrm{CO}_{2}$ emissions? A Pigouvian ${ }^{140}$ carbon tax would set the level at the amount of marginal social damages for each ton of $\mathrm{CO}_{2}$ emitted. ${ }^{141}$ However, the actual, present-value damages of climate change over the next hundred years or so are sharply disputed among economists studying the economic effect of climate change. Estimates are extremely sensitive to a number of assumptions, most prominently the appropriate discount rate to be used in weighting future costs and benefits. ${ }^{142}$ The

138. The statistical accuracy of $\mathrm{CO}_{2}$ estimation methods is plus-or-minus thirteen percent, with a ninety-five percent level of confidence. GREENHOUSE GAS EMISSIONS, supra note 128, at 4-4 to 4-6; see also Metcalf \& Weisbach, supra note 129 , at 530 .

139. Metcalf \& Weisbach, supra note 129, at 531-32 ("Requiring monitoring of all landfills and including their emissions in the tax base should be relatively straightforward.”).

140. A Pigouvian tax is a unitary tax levied to make an emitter pay for the damages caused by its emissions, which are often invisible, or "external," to the emitter. The purpose of a Pigouvian tax is to make emitters face these external, invisible costs, or "externalities," and make them pay-no more, no less. ALFRED C. Pigou, The Economics of Welfare 131-35 (1928). Taxes that reflected the extent of negative externalities thus became known as "Pigouvian" taxes. William J. Baumol \& Wallace E. OATes, The Theory of EnVIRonmental PoLICY 21-23 (Cambridge Univ. Press 1988) (1975).

141. In theory, if the Pigouvian tax were to exactly price the marginal level of social damages, the tax rate would vary according to how much marginal damage was being imposed, right at that level of emissions. In practice, of course, such a floating rate would be administratively infeasible.

142. A plethora of modeling assumptions makes a huge difference in marginal damages estimates. One of the most influential studies, by William Nordhaus and Joseph Boyer, estimated in 2000 that the marginal social damages of the emission of one ton of $\mathrm{CO}_{2}$ were $\$ 2.48$, WILLIAM D. NORDHAUS \& JOSEPH BOYER, WARMING THE WorlD: ECONOMIC MODELS OF GLOBAL WARMing 91 tbl.4-10 (2000), an estimate that Nordhaus recently upped to about $\$ 7.50$, WILLIAM NORDHAUS, A QUESTION OF BALANCE 90 tbl.5-4 (2008). This contrasts quite dramatically with 
range of estimates of marginal social damages of a ton of $\mathrm{CO}_{2}$ is huge: A 2005 survey found a range of estimates from zero to over a thousand dollars per ton. ${ }^{143}$ The best pair of bookends for the disagreement includes one estimate by economist William Nordhaus $\left(\$ 7.50 \text { per ton of } \mathrm{CO}_{2}\right)^{144}$ and another by Nicholas Stern, the author of the UK-commissioned Stern Review ( $\$ 85$ per ton of $\mathrm{CO}_{2}$ ). ${ }^{145}$ Numerous methodological differences highlight a sharp intellectual divide between the two eminent economists, ${ }^{146}$ but more than anything, the divide illustrates how challenging it is to try to set a carbon tax at a level that economists could agree constitutes a comprehensive policy response to climate change.

In part because of this, my other work has advocated setting a low carbon tax that would be less controversial and would serve as just a first step in addressing climate change. ${ }^{147}$ Of course, even a small carbon tax is likely to generate political heat, but, at least among climate change economists, there is likely to be wide agreement that a small carbon tax is better than nothing. ${ }^{148}$ By the same reasoning, I also recommend that

the estimate obtained by the UK government-commissioned Stern Review, by Nicholas Stern, a former chief economist with the World Bank, which estimated current marginal damages at about $\$ 85 / \mathrm{tCO}_{2}$ (in year 2000 dollars, to provide a comparison with Nordhaus and Boyer). STERN, supra note 1, at 287. A very large part of this disparity can be accounted for by the two studies' difference in discount rates. Stern assumes a pure rate of time preference of roughly zero, $i d$. at 35-37, while Nordhaus uses a more conventional rate of three percent, NORDHAUS, supra, at 95.

143. Richard S.J. Tol, The Marginal Damage Costs of Carbon Dioxide Emissions: An Assessment of the Uncertainties, 33 ENERGY POL'Y 2064, 2068-69 tbl.2 (2005).

144. NORDHAUS, supra note 142 , at 90 tbl.5-4.

145. STERN, supra note 1, at 287. A primary reason for the difference between the two estimates is the difference in assumed discount rates, with Stern using a very low discount rate, id. at 35-37, and Nordhaus a more conventional one, NORDHAUs, supra note 142 , at 95.

146. Both Nordhaus and Stern include estimates of the costs of catastrophic risks, but Stern assumes higher likelihoods and greater costs. The Stern Review includes estimates of non-market impacts, which it describes as "impacts on the environment and human health," STERN, supra note 1, at 161, which would include impacts on wildlife and unpriced effects on human health such as increased spread of disease due to climatic changes, $i d$. at 293. Nordhaus finds these costs a bit speculative. NoRDHAUs, supra note 142, at 95.

147. HsU, supra note 105, at 29.

148. A proposal by three think tanks of varying political orientations, the American Enterprise Institute, the Breakthrough Institute, and the Brookings Institution, introduced a "post-partisan" proposal after the collapse of climate proposals in the U.S. Congress in 2010. The proposal emphasized small subsidies and a small carbon tax. Steven F. Hayward et Al., Post-Partisan Power: How A Limited AND Direct ApProach to EnERgy InNovation CAN DELiver Clean, 
this proposal steer as clear as possible of political turmoil by initially setting the carbon tax at a low level. This proposal is not intended to be a climate policy to end all other policies but rather is meant to generate a market for climate information. The carbon tax or cap-and-trade liabilities under this proposal would therefore be in addition to those imposed by any other climate policies. Of course, if anomalous climate outcomes that are part of the index became frequent enough, the carbon tax would be pushed higher and become very expensive and perhaps serve as a regulatory tool after all. If that turns out to be the case, the costs of compliance would be the least of our worries.

A carbon tax in the neighborhood of Nordhaus's $\$ 7.50$ estimate of the marginal social damages seems to be a good starting point. A wide range of economists would agree that the marginal social damages are at least that and would endorse such a tax level. ${ }^{149}$ The indexed carbon tax level should be adjusted for inflation to ensure that prices for tradable permits keep pace with market prices for other goods, thereby keeping constant the budgetary effects of the indexed carbon tax on emitters. Finally, to smooth out some of the potential volatility in this carbon tax, it could be indexed not just to the basket of outcomes from the previous year but to a moving average of the climate outcomes over a period of time. While the moving average period may not, and need not, capture very long-term climatic cycles, even an average of the previous five or ten years can smooth out some of the year-to-year variations in weather by diluting the effects of one or more exceptional years.

\section{Which Climate Outcomes?}

In addition to these two basic carbon tax questions, this proposal requires resolution of a third, more complicated matter: construction of the index to which the carbon tax level is linked. Toward this end, the basket of climate outcomes that make up the index should be composed of outcomes that (1) are

Cheap Energy, Economic Productivity And NAtional ProsPerity 7 (2010), available at http://thebreakthrough.org/blog/Post-Partisan\%20Power.pdf.

149. Nicole Heller \& Douglas Fischer, What's the Economic Impact of Climate Change? Pick a Number, Climate CENT. (Jan. 27, 2011), http://www.climatecentral.org/blogs/whats-the-economic-impact-of-climatechange-pick-a-number (showing that the vast majority of studies indicate a marginal cost much larger than $\$ 7.50$ per ton). 
non-manipulable and (2) are or can be reliably, regularly, and uncontroversially counted or measured. Prediction markets can only function if the outcomes are clearly defined and the rules for adjudication are stable. ${ }^{150}$ But beyond these basic reliability criteria, the question of which climate outcomes should be part of the index also forces us to confront the question of what exactly we wish the index to achieve. First, to keep the index focused on climate science, the climate outcomes included in the index should truly be climatological effects and not indirect, second-order ecological events caused by climate changes. Second, the index should capture a broad array of climate conditions while balancing the impacts that different outcomes will have on the index. That is, the index should provide a measure of all of the ways that climate change will affect humankind but without over-emphasizing any particular way that climate change will affect humankind.

As an example of how climate outcomes should be firstorder climatological effects and not indirect, second-order ecological effects, one might consider the inclusion of forest fires as a climate outcome. Counting forest fires that become more frequent or more damaging due to warmer and drier weather, ${ }^{151}$ or counting the forestry industry losses from heatstressed dieback, ${ }^{152}$ may seem more relevant and more directly connected to human loss. Not only that, but a solid body of research seems to support the notion that a climate-changed future will lead to these ecological outcomes. ${ }^{153}$ But focusing on outcomes that are more closely linked to the increase in greenhouse gases would ensure that the index is a gauge of the real, unavoidable threats posed by climate change. If the index could be changed by, for example, a widespread change in fire suppression practices, then it would not be an index of climate change but an index of climate change and how humans respond to it. Similarly, while forest fires and the pine-beetle outbreaks can be reasonably tied to climate change, so can monoculture-dominated forestry practices. ${ }^{154}$ Including second-

150. Wolfers \& Zitzewitz, supra note 82, at 120.

151. Anthony L. Westerling, Wildfires, in Climate Change ScIEnce AND PoLICY 92, 93-94 (Stephen H. Schneider et al. eds., 2010).

152. Phillips et al., supra note 111, at 1346.

153. See supra notes 151-52.

154. C.S. Holling \& Gary K. Meffe, Command and Control and the Pathology of Natural Resource Management, 10 CONSERVATION BIOLOGY 328 (1996); John Nowak et al., The Southern Pine Beetle Prevention Initiative: Working for Healthier Forests, 106 J. FORESTRY 261, 262-63 (2008). 
order outcomes would make for a noisier prediction market in which human interventions could interfere with the market signals on the quality and importance of climate science.

Second, some attention should be paid to the relationship among the different climate outcomes that make up the index. Where climate outcomes are not orthogonal to each other-i.e., where they are statistically or climatically related-some accounting should be employed so that different aspects of the same climate phenomenon are not double-counted or overweighted. For example, extreme droughts and extreme rainfall events are both part of the same climate phenomenon (the intensification of the hydrologic cycle) ${ }^{155}$ and are thus not orthogonal. Including both extreme rainfalls and extreme droughts in the index is useful because the two types of events may not occur in lockstep and will likely occur in different parts of the world, but some under-weighting is appropriate. And to some extent, some non-orthogonality will be unavoidable-given the limits of climate science, we may not even know if outcomes are orthogonal or not. But some attention to the relatedness of different climate outcomes is warranted.

Based on these criteria and taking these factors into consideration, the carbon tax should be indexed to the following six types of climate outcomes. A precise weighting of the six climate outcomes is left to future development. Some supplementary discussion of these outcomes is set out in the Appendix.

1. Global mean temperature. The core part of Professor McKitrick's proposal ${ }^{156}$ is surely on the mark: If one were to pick just one proxy for the severity of climate change, temperature would almost certainly be the best one. In the simplest physical terms, trapping heat within the Earth's atmosphere means that more energy is staying within the Earth's system, which means that the temperature will rise. Trapped heat will have other effects, so that temperature alone would not form a complete index, but it is surely a fundamental indicator of climate change.

The most general and reliable temperature statistic is the global mean temperature, which is the temperature averaged over an entire year and over the entire planet. This is not

155. See Thomas G. Huntington, Evidence for Intensification of the Global Water Cycle: Review and Synthesis, 319 J. HYDROLOGY 83, 83 (2006).

156. McKitrick, supra note 101, at 118. 
necessarily a straightforward measurement; weather monitoring in some places in the world is spotty, and because weather stations are irregularly spaced throughout the world, some statistical manipulation is necessary to reconstruct the temperature that evenly represents the whole planet. This has been the source of considerable controversy but, as discussed in the Appendix, should not interfere with the construction of this element of the index.

It should be noted that because temperature is such a good proxy for climate change, it is clearly not orthogonal to other climate outcomes. But this is not a reason to exclude temperature. Some climate outcomes, such as harm to ecosystems and loss of biological diversity, would be difficult to quantify and include in an index. It would thus be appropriate to weight temperature readings to try to reflect these unquantifiable harms that are orthogonal to other climate outcomes.

2. Days of unusually high or low temperatures. While global mean temperature is a vital statistic, using just one temperature is incomplete in several ways. First, it fails to capture the full range of climate effects that are regionally unique. Temperature changes in a climate-changed world will be heterogeneous. Polar regions will probably experience the most dramatic climatic changes, ${ }^{157}$ so that a single temperature reading will not quite reflect the degree of change in the polar regions.

Second, climate change is not limited to warming and may impose as much harm from unusually low temperatures as it does from high temperatures. ${ }^{158}$ Relying only on one temperature allows these two types of opposite extremes to cancel each other out, concealing the extreme events that are the most serious source of climate harm. High temperature extremes are associated with many costly climate effects, such as forest fires, ${ }^{159}$ heat waves that lead to deaths in vulnerable

157. See, e.g., IPCC FourTH AsSESSMENT, supra note 26, at 766-67 figs.10.8 \& 10.9 .

158. For example, current climate conditions sustain an Atlantic Ocean circulatory pattern that keeps Europe warm by bringing warm air northward from the tropics. One potential effect of climate change would be the shutdown of this circulatory pattern-the Atlantic Thermohaline Circulation-which would make Europe so cold as to be uninhabitable. See, e.g., HENSON, supra note 48, at $119-22$.

159. See Westerling, supra note 151 , at $93-94$. 
human populations, ${ }^{160}$ and a variety of ecological effects that impose indirect but potentially large costs upon society. ${ }^{161}$ Unusually low temperature extremes, widely considered to be a part of climate change, ${ }^{162}$ also impose costs on cities, agricultural industries, and other staples of society that are illprepared to deal with cold-weather events such as record frosts and snowfalls. ${ }^{163}$ Some statistical transformation needs to be made of the raw temperature data.

The index should include a broad basket of temperature readings from weather stations throughout the world to capture all of the different regional changes. And to make this data meaningful, the raw temperature readings should be transformed into counts of days with extreme temperatures. For each reporting weather station made a part of the index, an annual (or periodic moving average) count should be made of days in which unusually high and unusually low temperatures are reached. This definition of this climate outcome operationalizes regional variations in climate change, cold as well as hot anomalies, and the truly harmful events-extreme temperature (hot and cold) situations. Further details on quantifying this climate outcome are provided in the Appendix.

160. It was estimated that the summer heat wave that struck Moscow in 2010 nearly doubled the number of daily deaths. Death Rate Doubles in Moscow as Heat Wave Continues, BBC NEWs (Aug. 9, 2010), http://www.bbc.co.uk/news/ world-europe-10912658. The heat wave has been estimated to have caused 7,000 deaths in Moscow alone and 15,000 in Russia overall and to have decreased Russia's GDP by fifteen billion dollars. Lucian Kim \& Maria Levitov, Russia Heat Wave May Kill 15,000, Shave \$15 Billion of GDP, BlOOMBERG (Aug. 10, 2010), http://www.bloomberg.com/news/2010-08-10/russia-may-lose-15-000-lives-15-

billion-of-economic-output-in-heat-wave.html.

161. For example, damages to wetlands could undermine some of the ecosystem services that are provided, such as water filtration, flood control, and feeding grounds for migratory waterfowl. Climate change could affect water systems that are major water sources for population centers. And finally, loss of biological diversity worldwide could deprive humankind in a wide variety of ways, such as depriving it of medicinal resources, disrupting predator-prey relationships so that pests become more prevalent, or allowing some pests to become disease vectors. See, e.g., Rik Leemans, Ecosystems, in Climate CHANGE ScIENCE AND POLICY, supra note 1 , at 56, 57-61.

162. Henson, supra note 48, at 55-56; Wayne Higgins et al., The Facts About Snowstorms \& Climate Change, NAT'L OCEANIC \& ATMOSPHERIC ADMIN., http://www.noaa.gov/features/02_monitoring/snowstorms.html (last visited Feb. $25,2011)$.

163. An unusual number of snowstorms affecting New York City imposed substantial costs, including loss of revenue from parking meters buried under snow. Manny Fernandez, Crime Down, Bills Up: How Snow Affects the City, N.Y. TIMES, Feb. 11, 2011, at A23. 
3. Extreme rainfall and drought events. One of the ironies of climate change is that it will make water both more abundant and more scarce. In neither case, however, will this be helpful. Climate change will intensify the hydrological cycle, leading to both increased instances of flooding and drought, and probably, in different places, making water supply management much more difficult (if not impossible). ${ }^{164}$ Again, if one were to simply take a total rainfall number as a climate outcome, the aggregated number would conceal the extremes that are most harmful. Part of the index should thus capture the occurrence of precipitation extremes, just as it captures temperature extremes.

Costs from extreme rainfall events and drought in the United States could be as much as $0.5 \%$ of GDP, ${ }^{165}$ or about seventy billion dollars. ${ }^{166}$ Of the two, extreme drought seems less manageable, as life without water is impossible. Adapting to extreme rainfall, however, would only be more manageable if vital infrastructures to capture and store water were dramatically upgraded or fundamentally altered, measures that are probably out of the reach of most developing countries. The different nature of the harms of extreme rainfall and drought seems to warrant separate measurement in the index. Again, details on how to define and count extreme rainfall events and droughts are set forth in the Appendix.

4. Rises in sea level. If there is one climate outcome that has alarmed people, it is the prospect of rising sea levels that jeopardize trillions of dollars of real estate worldwide. ${ }^{167}$ In reality, the most expensive real estate is in developed countries, which have the resources and the engineering skills to construct sea walls to protect certain cities. ${ }^{168}$ While climate change may tax the capacity of dikes in the Netherlands, some of which have been designed to withstand 10,000 years' worth

164. See, e.g., Henson, supra note 48, at 58; Peter H. Gleick, Water, in Climate Change SCIEnCE AND POLICY, supra note 1, at 74, 75-76.

165. Gleick, supra note 164 , at 78.

166. The estimated 2009 GDP of the United States is slightly over fourteen trillion dollars. The World Factbook: United States, CIA, https://www.cia.gov/ library/publications/the-world-factbook/geos/us.html (last visited July 8, 2011).

167. See Tim Lenton et al., Major Tipping Points in the Earth's Climate SYSTEM AND CONSEQUENCES FOR THE INSURANCE SECTOR 37 (2009), available at https://www.allianz.com/static-resources/en/press/media/documents/tipping_points .pdf (estimating a loss of one trillion dollars for New York City alone).

168. Id. at 34 . 
of storms, ${ }^{169}$ some engineering solutions do seem imaginable, if unattractive and possibly uneconomical. ${ }^{170}$ Perhaps most ominously, rising sea levels could lead to civil unrest, as some of the most vulnerable populations in low-lying areas such as the Ganges Delta in Eastern India and Bangladesh ${ }^{171}$ would find permanent migration necessary. Low-lying island countries, such as the Maldives and Tuvalu, could find it necessary to find entirely new homes for their permanently displaced populace, imposing an entirely new set of economic and diplomatic challenges. ${ }^{172}$

Moreover, for larger sea level rises, even some advanced countries will face enormous costs. With a rise of six meters in mean sea level, much of what is presently Florida would be uninhabitable. ${ }^{173}$ As there is still a fair amount of disagreement among climate scientists about the range of possible sea level rises attributable to climate change, larger values cannot be ruled out. Climate scientist James Hansen even believes that, with a $3^{\circ} \mathrm{C}$ increase in mean global temperatures, enough glacial melting at the poles could occur to bring on a catastrophic twenty-five-meter increase in mean sea levels, ${ }^{174}$ orders of magnitude greater than the IPCC's estimate of 0.22 to 0.44 meters. ${ }^{175}$ Few climate scientists share Hansen's level of alarm, ${ }^{176}$ but neither is it dismissed. Apart from the potential for harm from sea level rises, it is this kind of scientific uncertainty that might be best run through a prediction market.

5. Ocean acidity. As $\mathrm{CO}_{2}$ concentrations increase in the atmosphere, oceans absorb much of the $\mathrm{CO}_{2}$, taking up an estimated 500 gigatons of $\mathrm{CO}_{2}$, about thirty percent of fossil fuel emissions since 1800. ${ }^{177}$ This absorption has come at a cost of increasing the acidity of the ocean, thereby decreasing the

169. See Krystian W. Pilarczyk, Design Philosophy and Methodology, in DiKeS and Revetments: Design, Maintenance AND SAFety Assessment 11, 15 (Krystian W. Pilarczyk ed., 1998).

170. Id.

171. HENSON, supra note 48 , at 115 .

172. Id. at $112-13$.

173. Id. at 114 .

174. See J.E. Hansen, Scientific Reticence and Sea Level Rise, 2 ENVTL. RES. LETTERS 024002, at 3 (2007).

175. IPCC FOURTH ASSESSMENT, supra note 26, at 409 fig. 1.

176. HENSON, supra note 48, at 118.

177. Carol Turley, Marine Ecosystems, in Climate Change ScIEnce AND PoLICY 66, 68 (Stephen H. Schneider et al. eds., 2010). 
mean $\mathrm{pH}$ of the world's oceans by $0.1{ }^{178}$ This is a subtle but potentially much more costly and harmful effect than a rise in sea level, as the disruption of marine ecosystems could lead to a crash in marine food chains ${ }^{179}$ that sustain an enormous fraction of the world's population and currently contribute almost $\$ 250$ billion per year to the world economy. ${ }^{180}$ Coral reefs, in particular, are believed to be vulnerable to even small changes in acidity and are believed to play an important role in maintaining biological diversity in oceans. ${ }^{181}$ If a severe decline in ocean life and a serious disruption to the marine food chain occurs, the damages would well exceed $\$ 250$ billion, since the value of something like food is far greater than what the market price would suggest, especially when it becomes scarce. While it is difficult to ascertain how harmful changes in acidity will be to humankind, this is clearly an important climate effect to include in an index.

6. Hurricanes above a certain intensity level. Hurricanes are hypothesized to increase in severity with increases in sea surface temperature, and increases in sea surface temperature are believed to be a consequence of the trapping of heat by greenhouse gases. ${ }^{182}$ But there is no current scientific consensus on a link between hurricanes and climate change. ${ }^{183}$ There is, however, a great deal of attention and research, especially following the publication in 2005 of two articles, one by M.I.T. atmospheric scientist Kerry Emanuel, ${ }^{184}$ and one by a

178. Henson, supra note 48 , at 124 .

179. See, e.g., The Royal Soc'Y, OCEAn ACIDIFICATION Due to InCREASING ATMOSPHERIC CARBON DIOXIDE 15 (2005), available at http://royalsociety.org/ WorkArea/DownloadAsset.aspx?id=5709; Christopher L. Sabine et al., The Oceanic Sink for Anthropogenic $\mathrm{CO}_{2}, 305$ SCIENCE 367 (2004).

180. Andrew J. Dyck \& U. Rashid Sumaila, Economic Impact of Ocean Fish Populations in the Global Fishery, 12 J. BiofConomics 227, 227 (2010).

181. See HENSON, supra note 48, at 125-26.

182. See, e.g., J.A. Curry et al., Mixing Politics and Science in Testing the Hypothesis That Greenhouse Warming Is Causing a Global Increase in Hurricane Intensity, 87 BULL. AM. METEOROLOGICAL SOC'Y 1025, 1032 (2006); Kerry Emanuel, Increasing Destructiveness of Tropical Cyclones over the Past 30 Years, 436 NATURE 686, 686-88 (2005); Thomas R. Knutson, Has Global Warming Affected Atlantic Hurricane Activity?, GEOPHYSICAL FLUID DYNAMICS LABORATORY (Sept. 3, 2008), http://www.gfdl.noaa.gov/global-warming-andhurricanes.

183. See Curry et al., supra note 182, at 1032. A significant problem is that the worldwide record of storms is not very long, dating back only to 1851 for North American storms, id., and 1949 for global storms, Hurricane/Tropical Data, supra note 114 .

184. Emanuel, supra note 182. 
team at Georgia Tech, ${ }^{185}$ which coincided with Hurricane Katrina (which has not been attributed to climate change). Current thinking among most climate scientists studying the effects of climate change on hurricanes is that climate change may produce more intense hurricanes, but not necessarily more of them. ${ }^{186}$ An index of climate outcomes may thus include a count of more severe hurricanes, not a raw count of all hurricanes.

As discussed above, "deadliness" and "costliness" are not the correct ways to think about inherent climate harm. The existence of potential avoidance and mitigation actions, ex ante and ex post, means that these measures could be internally inconsistent, varying from one hurricane to the next depending on the (climatically) irrelevant factor of where the hurricanes made landfall. ${ }^{187}$ Nevertheless, if there is a link between hurricanes and climate change, it is one of the few climate outcomes that would be orthogonal to global mean temperature and would capture a climate harm not captured by other outcomes.

Constructing an index for a carbon tax thus turns out to be a fairly tricky exercise. It raises not only some mundane but also some unexpectedly philosophical questions about climate change that challenge what we fear, know, and wish to know about climate change. A number of other possible climate outcomes could be defensibly included in an index. ${ }^{188}$ Over time, it may become apparent that other climate outcomes should have been included at the outset. Answering these questions and constructing the index with precision, however,

185. P.J. Webster et al., Changes in Tropical Cyclone Number, Duration, and Intensity in a Warming Environment, 309 SCIENCE 1844 (2005).

186. See, e.g., Curry et al., supra note 182; Emanuel, supra note 182.

187. See Jerry D. Jarrell et al., The Deadliest, Costliest, and Most Intense United States Hurricanes from 1900 to 2000, ATLANTIC OCEANOGRAPHIC \& METEOROLOGICAL LABORATORY, http://www.aoml.noaa.gov/hrd/Landsea/deadly (last updated Oct. 2001).

188. For example, another potential climate outcome could be Arctic Ocean sea ice extent. Melting Arctic sea ice has long been thought to be one of the most alarming consequences of climate change, as it portends a palpably dramatic change in the Arctic environment. See HENSON, supra note 48, at 75. The National Snow and Ice Data Center in Boulder, Colorado, is of the opinion that "[l]ong-term changes in Arctic sea ice are an index of climate change." Sea Ice Index, NAT'L SNOW \& ICE DATA CENTER, http://nsidc.org/data/seaice_index (last visited June 13, 2011). However, it is not clear that sea ice extent would be a better indicator than a count of the number of days of unusually high temperatures for an Arctic weather station, which would be part of climate outcome number two. 
is not as important as the overall goal of the proposal-to run climate science through a market filter and neutralize the political partisanship and disingenuous posturing that has tainted the debate. However, because the problem of climate change is so important, and the stakes so large, it is worth spending some time to get the details of the indexed carbon tax right.

\section{B. The Cap-and-Trade Program}

The establishment of a cap-and-trade program to act as essentially a prediction market for future climate outcomes gives rise to the other set of tricky implementation questions. As a cap-and-trade program, it raises the usual implementation questions, plus those that are unique to this program's situation in a carbon tax environment. One of the usual implementation questions is that of which entities should be covered (required to hold permits for their emissions). Under most cap-and-trade programs, being covered is a burden; in this program, the cap-and-trade system is for permits that represent an exemption to the indexed carbon tax, and are thus an opportunity to lower the regulatory costs, rather than just minimize them through trading. As the indexed carbon tax is proposed to apply upstream to all coal mines, natural gas processors, oil refineries, and fossil fuel importers, ${ }^{189}$ these are the entities that must be allowed to hold permits in lieu of paying the carbon tax. Of course, other entities and other people are allowed to buy and sell permits; this proposal depends vitally on widespread market participation as a means of aggregating the widely disparate pieces of information about climate science. The program-scoping question thus resolved by virtue of its link to the carbon tax, this Article now turns to the remaining issues involved in setting up the cap-and-trade program: the initial allocation of permits and the timing and quantity of permits to be issued.

\section{Initial Allocation of Permits}

The first and most obvious implementation question for setting up a cap-and-trade program is how to make the initial allocation of permits. Should they be auctioned or given away

189. See supra notes 129-35 and accompanying text. 
for free? If given away for free, should they be "grandfathered" in on the basis of historical emissions, or on the basis of some other politically-devised method of allocation? As an economic matter and a distributional matter, auctioning permits is almost always superior to giving them away for free. Not only does the latter effect a transfer from taxpayers to wealthy individuals (shareholders of emitting firms), but it also produces some economically distortionary effects. ${ }^{190}$ As a political matter, however, giving away permits to purchase political support, under the guise of "transition relief," is usually viewed as being necessary in order to obtain even a remote chance of legislative passage in the United States. ${ }^{191}$ It is apparently lost on no one that when a cap-and-trade program gives away permits, the legislature is essentially printing money, albeit an undetermined amount. ${ }^{192}$

The cap-and-trade part of this proposal differs from an ordinary cap-and-trade program in two respects that might render the free allocation of permits a little less irresistible and auctioning a little more politically palatable. First, the carbon tax is to be initially set at a low level so that the permit prices will be low and their value as transition relief concomitantly low. Second, permit prices in this program will not be driven by scarcity, as they are in pure cap-and-trade programs, but rather by expectations of future climate outcomes. The trading market for permits to emit in the distant future could be very thin. Those emitters given free permits may conclude that the simplest option in the near term is to wait and see what happens in the near- and medium-run. If that turns out to be a common strategy, then the value of those free permits may be quite low. With low prices, it would also make the economic pain of buying permits less acute. A thin trading market would also mean that the market would be missing an important opportunity to collect a valuable piece of information: the auction price. For these reasons, the permits to emit in future years in this proposal should be auctioned rather than given away for free.

190. See, e.g., HsU, supra note 105, at 61-62; Dallas Burtraw et al., The Incidence of U.S. Climate Policy: Alternative Uses of Revenues from a Cap-andTrade Auction 2 (Res. for the Future, Discussion Paper No. 09-17-REV, 2009), available at http://ssrn.com/abstract $=1392251$.

191. See HSU, supra note 105, at 120-21; Jonathan S. Masur \& Jonathan Remy Nash, The Institutional Dynamics of Transition Relief, 85 N.Y.U. L. REV. 391, 393 (2010).

192. HSU, supra note 105 , at 62 . 


\section{How Far in Advance Should Permits Be Available?}

As the point of a cap-and-trade program is to process information about future climate conditions, it is important to decide how far in advance permits should be available. Of course, if permits were not tradable, then asking firms to bid on permits many years in advance might ask too much in terms of information. But it is the trading activity subsequent to initial acquisition through auction that will yield the most important information. Obviously, as the vintage year of a permit approaches, one should expect the price of the permit to be a better estimate of the actual prices and a better anticipation of climate outcomes. Just as obviously, in evaluating the market signals produced by this program, some consideration must be made of the time value of money. If a firm is buying a permit to avoid a carbon tax thirty or forty years in the future, then it can be expected to discount that future carbon tax liability substantially, paying much less for permits to emit far in the future than it would for permits to emit in the next year or two.

As a starting point, the failed American Clean Energy and Security Act of $2009^{193}$ (a.k.a. Waxman-Markey, after the cosponsors) and the Clean Energy Jobs and American Power Act $^{194}$ (a.k.a. Kerry-Lieberman, after the co-sponsors) contemplated a cap-and-trade system out to 2050. Also, California's AB 32, its landmark climate change legislation, includes a cap-and-trade program that contemplates a reduction of greenhouse emissions by eighty percent by the year 2050. ${ }^{195}$ An auction of permits forty years in advance would thus prima facie seem reasonable.

There is the objection that such a long time horizon seems Pollyannaish since emitters may not believe that this proposal, if enacted, would stay intact for forty years. If that were the case, then there would be very little interest in bidding for permits more than a few years down the road. WaxmanMarkey and Kerry-Lieberman, one might snort, could afford to

193. H.R. 2454, 111th Cong. § 321 (2009), available at http://www.govtrack.us/ data/us/bills.text/111/h/h2454pcs.pdf.

194. S. 1733, 111th Cong. § 111 (2010), available at http://www.govtrack.us/ data/us/bills.text/111/s/s1733rs.pdf.

195. Cap-and-Trade, AIR Resources BoARD, CAL. Envtl. Protection AGENCY, http://www.arb.ca.gov/cc/capandtrade/capandtrade.htm (last visited July 8, 2011). 
be unrealistically optimistic because, even if one believed that targets in 2050 would remain intact, many near- and mediumterm greenhouse gas emission reductions would take place, and those reductions were the most important objective of climate legislation anyway.

The response to this objection is that participation in a program like this would create its own policy stability: those who spend money on buying auctioned permits would oppose an abandonment of a program such as this, as that would leave them with valueless permits. This would especially be true if some emitters felt that they had been clever enough to have obtained future permits at a low price and thus stand to lose out if the program is stopped. Unlike most cap-and-trade programs, this proposal explicitly contemplates making emitters think far in advance and plan for the fairly distant future. Once investments are made in reliance on this program, dismantling it would become politically and perhaps economically costly. So a cap-and-trade program could be designed with a little bit of optimism about the prospects for its survival and credibility. And since the purpose of a cap-andtrade program is to generate and evaluate information about climate conditions with long time horizons, this program would not be useful unless it sold permits for vintage years far in the future. Looking ahead forty years, as did the Waxman-Markey and Kerry-Lieberman bills, does not seem overly optimistic.

\section{How Many Permits Should Be Available for a Vintage Year?}

It is worth being careful about how many permits to make available for each vintage year. A target amount of permits would have to be large enough to create a real market, one that is large enough to mobilize interest in evaluating climate science. The number of available permits should be large enough to ensure a robust market that reveals significant information about opinions of climate science. But the number of available permits should also not be too large. A surfeit of permits could drive the market price below the indexed carbon tax, which would create the risk that this hybrid program would simply morph into a pure cap-and-trade program. This program would lose the benefit of having the cap-and-trade program actually reveal information about opinions of climate science. 
This over-allocation danger should also be borne in mind when considering the possibility of another, more ambitious climate policy with an explicit goal of reducing greenhouse gases (unlike this proposal, which is primarily aimed at generating information about climate science). If at any time, for any reason, emissions fall below the number of extant permits available, the price of permits will be driven to near zero. For example, if a more ambitious policy drives emissions lower than the number of extant permits under this tax-andcap-and-trade program, then there will be more permits available than are needed to permit emissions. There would be no scarcity of permits at all, and no prices to generate information about climate science, stripping this proposal of any informational benefits. So determining the extant number of permits to make available involves a moving target, taking into account the possibility of future policy advances that might curtail future emissions.

A little back-of-the-envelope math would help the reader gain a rough idea of how many permits should be available for each year. Consider that world emissions of $\mathrm{CO}_{2}$ were approximately 30.55 gigatons in 2007, 5.97 of which were emitted by the United States. ${ }^{196}$ Even if, assuming optimistically, some legislation such as Waxman-Markey comes back to pass in a future Congress and that an eighty percent reduction is achieved, that would still mean that roughly 1.2 gigatons of $\mathrm{CO}_{2}$ would be emitted in the United States in 2050. If the cap-and-trade program issued, say, one-third of that emissions total, 400 million permits of vintage year 2050 should be made available. In the interests of maintaining some consistency in terms of the amount of climate information generated for each future year, the number of permits available each vintage year should be uniform, necessitating some scheduling of permit auctions. A proposed schedule is set forth in the Appendix.

Is this enough of a market to meet the program's goals of generating interest among emitters in participating? Assuming, just for the purpose of a rough calculation, a trading price of $\$ 5$ per permit - that the best forecasts for the indexed carbon tax would be about $\$ 5$ per ton-the cap-and-trade program would create a $\$ 2$ billion market, $\$ 50$ million of which

196. World Res. Inst., Climate Analysis Indicators Tool: Total GHG EMISSIONS IN 2007 (2011) (total world emissions are obtained by dividing U.S. emissions by its fraction of world emissions). 
is added each year. As noted earlier, AEP's 2005 emissions would have produced a carbon tax liability of about $\$ 805$ million, ${ }^{197}$ assuming that it does not reduce emissions. The liability of the top 101 emitters would be about $\$ 8.75$ billion. ${ }^{198}$ It could be much higher if dangerous climate outcomes become unexpectedly frequent. That would appear to be enough to mobilize interest in forecasting climate outcomes and the resulting indexed carbon tax.

Cap-and-trade programs invariably require resolution of a number of design issues. This Article proposes the simplest resolutions of two fundamental cap-and-trade design issues: how permits are allocated (by auction) and who is covered (everyone, upstream). In addition, this Article suggests some parameters for some of the design issues that are specific to this proposal, ones that will determine how useful this program is to aggregating and processing climate science.

\section{Competitiveness and Trade Concerns}

This proposal could be the subject of national, state, or provincial legislation, or of a regional program among states and provinces, or indeed a program among almost any combination of jurisdictions. But whatever its constituents, an important consideration in adopting this proposal is what, if anything, to do about the competitiveness of firms, vis-à-vis those outside of the jurisdiction that do not face the costs of a carbon pricing program such as this one. This Section addresses this problem, working from an assumption that the program is a national one.

The climate change problem is unique in the overwhelming incentive it produces to free-ride. The harder one country tries to reduce its $\mathrm{CO}_{2}$ emissions by reducing fossil fuel use, the greater downward pressure on fossil fuel prices (due to the resulting decrease in demand), the greater the temptation for other countries, especially developing ones, to snap up the suddenly abundant and cheap fossil fuel. ${ }^{199}$ And finally, this proposal would appear to even further exacerbate that cruel dynamic: A carbon tax indexed to climate outcomes could very

197. Clean Energy, supra note 116.

198. See supra text accompanying note 126

199. See, e.g., Shi-Ling Hsu, A Game-Theoretic Model of International Climate Change Negotiations, 29 N.Y.U. ENVTL. L.J. (forthcoming 2011), available at http://ssrn.com/abstract=1573054. 
well increase in part because of the emissions of other, noncooperating countries, since $\mathrm{CO}_{2}$ emissions anywhere contribute to climate changes everywhere. American industries subjected to this tax-and-cap-and-trade program could wind up paying more carbon taxes because China is uncooperative and emitting greater amounts of $\mathrm{CO}_{2}$.

There are two responses built into the structure of this proposal: (1) the revenues from both the carbon tax and the auction proceeds from the cap-and-trade part can be used for transition relief, and (2) this tax-and-cap-and-trade program, if implemented, may provide a legitimate basis for levying a border tax adjustment on imports from countries that do not price carbon. ${ }^{200}$

First and foremost, this tax-and-cap-and-trade proposal, like other proposals, creates a source of revenue. As suggested earlier, some of these revenues can be targeted at communities that suffer damages from climate events or used to fund adaptation measures. But another potential use for the revenues is to provide some relief for industries that face competitive pressures from firms in countries that do not price carbon. What little evidence that is able to rise above the handwringing suggests that the amount of "offshoring" of both manufacturing and emissions is relatively small and possibly exaggerated to serve protectionist purposes. ${ }^{201}$ Nevertheless, to the extent that this policy could provide some palliative for industries feeling a bit vulnerable, it is an advantage that many other climate policies do not have. Granted, while transition relief provided from the proceeds of this proposal could not make emitters whole, it could provide some incentives and support for carbon-intensive and trade-exposed

200. This latter consideration does not apply if the proposal is carried out as a state, provincial, or regional program.

201. Trevor Houser et Al., Peterson Inst. For Int'L Econ., Leveling the CARbon Playing Field: International Competition and US Climate Policy DESIGN 10 (2008), available at http://pdf.wri.org/leveling_the_carbon_ playing_field.pdf (showing that a carbon tax of ten dollars per ton would only reduce output by $0.5 \%$ ). Only eighteen percent of the steel, aluminum, cement, paper, and basic chemicals produced in the world are internationally traded. Id. at 77 . Although carbon pricing could increase this amount, it is not widely believed among economists to be likely to have much of an effect. Joost Pauwelyn, U.S. Federal Climate Policy and Competitiveness Concerns: The Limits and Options of International Trade Law 6 (Nicholas Inst. for Envtl. Policy Solutions, Working Paper No. 07-02, 2007), available at http://nicholasinstitute.duke.edu/ climate/policydesign/u.s.-federal-climate-policy-and-competitiveness-concerns-thelimits-and-options-of-international-trade-law/at_download/paper. 
industries to re-examine old assumptions about the need to emit greenhouse gases. And the revenues available to accomplish this are not trivial; even at a low carbon tax rate of $\$ 5$ per ton, if it covered all fossil fuel emissions in the United States, the combined proceeds from the tax and the cap-andtrade program would total about $\$ 30$ billion annually at present emission rates. ${ }^{202}$ Even a small portion of that could go a long way toward transition relief.

Second, a carbon tax provides perhaps the best legal chance under international trade rules to levy a border tax adjustment on imports from countries that do not price carbon. World Trade Organization (WTO) panels and predecessor panels of the General Agreement on Tariffs and Trade (GATT) have had a mixed record when it comes to allowing countries to protect domestic industries disadvantaged by stronger environmental regulations at home. ${ }^{203}$ While WTO and predecessor GATT panels have been stingy in permitting trade relief on environmental grounds, based on provisions under the "General Exceptions" article (Article XX), ${ }^{204}$ they have been somewhat less skeptical when reviewing border tax adjustments under Article II. ${ }^{205}$ Article II.2(a) of the GATT provides that GATT's prohibitions on tariffs do not prevent a country "from imposing at any time on the importation of any product ... a charge equivalent to an internal tax ... in respect of the like domestic product or in respect of an article from which the imported product has been manufactured or produced in whole or in part."206 "Internal taxes" are commonly interpreted as including sales taxes, excise taxes, or valueadded taxes.

The question is thus whether a carbon tax could be likened to other "internal" taxes that would justify a border tax adjustment under Article II. The international trade jurisprudence, such as it were, is sketchy and incomplete. From

202. U.S. emissions were about six gigatons of $\mathrm{CO}_{2}$ in 2007. WORLD RES. INST., supra note 196.

203. See, e.g., Daniel C. Esty, Bridging the Trade-Environment Divide, 15 J. ECON. PERSP. 113, 114 (2001); George Hoberg, Trade, Harmonization, and Domestic Autonomy in Environmental Policy, 3 J. CoMP. POL'y ANALYsis: Res. \& PRAC. 191, 195-207 (2001).

204. General Agreement on Tariffs and Trade art. XX, Oct. 30, 1947, 61 Stat. A3, 55 U.N.T.S. 187.

205. Pauwelyn, supra note 201, at 17.

206. General Agreement on Tariffs and Trade, supra note 204, 61 Stat. at A15, 55 U.N.T.S. at 202 (emphasis added). 
the literature that has emerged on this possibility, the consensus is a resounding "maybe." ${ }^{207}$ What does seem clear, however, is that a carbon tax is less vulnerable to a WTO challenge than many other climate policies in that it seeks to equalize a tax burden across trade borders. For cap-and-trade programs in which allowances are distributed for free, either on the basis of historical emissions or on some other politicallyderived formula, it would be difficult to make the case that a border tax adjustment sought to equalize a burden, since domestic emitters would already be benefitting from free allowances. In this regard, this tax-and-cap-and-trade program, insofar as it imposes unambiguous, unitary charges, would be a better platform from which to justify a border tax adjustment than other policies.

At least on an international level, then, this tax-and-capand-trade proposal would thus appear to have some economic resources and legal footing on which to address competitiveness and trade concerns. Even if such concerns are exaggerated, it cannot be an inefficient move to equalize carbon pricing burdens across borders, and it could well prove to be helpful in recruiting international cooperation on greenhouse gas emissions reduction.

\section{How Well Will the Market Work?}

As noted earlier, recent market travails have cast a shadow over markets as allocative mechanisms. ${ }^{208}$ More so than in the past, people distrust market prices as fundamental indicators of inherent value. ${ }^{209}$ In the long run, however, markets still provide the best chance of ascertaining value. There is still no institution that more rationally evaluates value.

207. See, e.g., Houser ET AL., supra note 201, at 30; Gary Clyde HufBauer ET AL., Global WARMing AND THE WorLD TRADING SYSTEM 39-46 (2009); Gavin Goh, The World Trade Organization, Kyoto and Energy Tax Adjustments at the Border, 38 J. WORLD TRADE 395, 422-23 (2004); Roland Ismer \& Karsten Neuhoff, Border Tax Adjustment: A Feasible Way to Support Stringent Emission Trading, 24 EUR. J. LAW \& ECON. 137, 143-52 (2007); Pauwelyn, supra note 201, at 17-23. But see DANiEl C. Esty, GREENING THE GATT-TRADE, ENVIRONMENT AND THE FUTURE 168 (1994).

208. See supra Part II.

209. See supra Part II. 
One objection is that irrationalities do creep into market evaluations, and the outcome can be spectacularly bad. ${ }^{210}$ When analysts' valuations are systemically errant-when they are systemically based on other analysts' errant evaluationsassumptions of widespread rationality break down, and a long chain of inaccurate valuations cascades throughout a market, skewing prices. When a critical piece of corrective information finally emerges, prices can be crushed almost instantaneously in an electronic era. But systemic error can persist for a long time before a correction. As Keynes famously remarked, "[m]arkets can stay irrational longer than you can stay solvent." 211

According to James Surowiecki, the author of the book The Wisdom of Crowds, the danger of systemic and cascading breakdowns in market accuracy emerges when evaluations lose independence from each other. ${ }^{212}$ The strength of markets and the advantage of the many are only present when a diverse body of people, thinking independently, make their own evaluations. Independence is so important because it ensures that groupthink does not form and that ideas are genuinely tested before individuals begin to adopt them. ${ }^{213}$

In this way, a prediction market in future climate outcomes - the cap-and-trade program-would make a virtue out of the exasperatingly deep divide between climate scientists and climate skeptics. Climate skeptics would, in all likelihood, make the market for climate information better, even if in the end they are proven wrong in their skepticism. It is the intellectual challenge posed to ideas that strengthens them. This was the way that the concept of the "marketplace of ideas" 214 was supposed to work. Something seems to have gone

210. See SUROWIECKI, supra note 86, at 41-43.

211. Maureen O'Hara, Bubbles: Some Perspective (and Loose Talk) from History, 21 REV. FIN. STUD. 11, 14 (2008).

212. See SUROWIECKI, supra note 86 , at 41-43.

213. See id.

214. This widely used market metaphor to support legal arguments for the First Amendment right to freedom of expression is attributed to a dissenting opinion by Justice Oliver Wendell Holmes in Abrams v. United States, 250 U.S. 616 (1919), but was never actually used by Justice Holmes. In Keyishian v. Board of Regents, another U.S. Supreme Court case, this one involving the constitutionality of a university's requirement that its faculty members certify that they were not Communists, Justice Brennan wrote that "[t]he classroom is peculiarly the 'marketplace of ideas.' The Nation's future depends upon leaders trained through wide exposure to that robust exchange of ideas which discovers truth 'out of a multitude of tongues, [rather] than through any kind of 
wrong in the marketplace for climate ideas, and a prediction market is likely to at least improve the situation. Because climate science and climate skepticism are both brutally crossexamined, a market in climate science would seem to be a poor host for systemic errors.

In addition to suffering systemic error, markets can be subject to conscious manipulation. Abramowicz discusses the possibility of market manipulation and reviews the literature on market manipulations, particularly in prediction markets. ${ }^{215}$ His tentative conclusion is that in markets possessing a great deal of public information, the empirical evidence does not support a fear of long-term effects from manipulation. ${ }^{216}$ If that is the case, then climate science, derived mostly from published data and analysis, should be a market that is uniquely insulated from manipulation. Wouldbe manipulators would be faced with trying to move prices in the face of an enormous amount of information, far more information than is ever made public with regard to the millions of publicly-traded firms whose shares are traded throughout the world.

A brief thought experiment in imagining a market for climate outcomes would provide some reassurance that a prediction market in climate science would be even less susceptible to manipulation. The findings and assertions of climate science are almost completely public (even if climate skeptics charge that climate scientists have been secretive about their data). Under the Abramowicz analysis of prediction markets, this predominance of public information would pose a significant obstacle for market manipulators hoping to bias a perception. The task of biasing opinion for a long enough period of time to profit would be enormously difficult, as it would be facing a barrage of countervailing assertions every day from both climate scientists and climate skeptics. While some industry groups and ideological groups have succeeded in biasing public opinion against concern about climate change, ${ }^{217}$ convincing those with a material interest in accuracy-such as AEP, with its potentially billions of dollars of annual carbon

\footnotetext{
authoritative selection.' " 385 U.S. 589, 603 (1967) (second alteration in original) (quoting United States v. Associated Press, 52 F. Supp. 362, 372 (S.D.N.Y. 1943)).

215. ABRAMOWICZ, supra note 82, at 28-32.

216. Id.

217. See, e.g., Boykoff \& Boykoff, supra note 20, at 133.
} 
tax liability-would be an entirely different matter with a continuing trove of research being produced daily.

Also, the sheer size of just a domestic U.S. market would make sustained market manipulation exorbitantly costly. By the rough back-of-the-envelope calculations above, ${ }^{218}$ with a market of about two billion dollars for each vintage year, and with a huge number of market participants likely to trade in emissions permits, it is inconceivable that anybody would find it worthwhile to try to sway the market in any meaningful fashion. For a cap-and-trade program whose value is indexed to a large basket of climate outcomes, one would have to not only skew one piece of information but also manipulate information about three or four or five climate outcomes.

Perhaps most relevantly, the few emissions permit markets that have been implemented thus far have shown no signs of either manipulation or cascading breakdowns due to systemic bias and error. The sulfur dioxide trading program has never drawn suspicions of market manipulation, even while attracting a considerable number of speculators that were not involved in the electricity generating industry at all. ${ }^{219}$ Nor have other subsequent programs, such as the European Union Emissions Trading System or the much smaller (and therefore potentially vulnerable) Regional Greenhouse Gas Initiative, involving only power plants in ten northeastern U.S. states. ${ }^{220}$ Prices have in some cases been volatile, ${ }^{221}$ and a source of consternation for some investors, but in no instance has a price movement been sustained for a long time or been cause for suspicion.

Finally, a question related to systemic error and manipulation is the question of whether there is enough information on which to trade. Is there or would there be enough climate science on which to trade? On what basis would firms buy permits to emit forty years in the future?

In thinking about this problem it is worth bearing in mind that not only do markets knit together disparate information and create incentives to reveal information, but they also

218. See supra text accompanying note 197.

219. See, e.g., A. Denny Ellerman et Al., Markets for Clean Air 7 (2000); Jacob Kreutzer, Cap and Trade: A Behavioral Analysis of the Sulfur Dioxide Emissions Market, 62 N.Y.U. ANN. SURV. AM. L. 125, 138 (2006).

220. REGIONAL GREEnHOUSE GAS InITIATIVE, http://www.rggi.org/home (last visited July 8, 2011).

221. HSU, supra note 105, at 71. 
create incentives to generate new information. ${ }^{222}$ Beyond public monies, private firms have already begun to get involved in the climate monitoring business. ${ }^{223}$ The prospect of more climate information may seem daunting to those already inundated by climate science, but few climate researchers, even as they advocate for strong policies to reduce greenhouse gases, would deny that huge data gaps remain. ${ }^{224}$

Again, because of the unprecedented size of this prediction market, the demand for new, better, and more predictive climate science will become apparent. Future multi-billiondollar carbon tax liabilities, even when discounted, will draw in even more climate researchers, potentially working in areas in which climate science is currently somewhat less developed, or areas that funding agencies may have completely overlooked.

It is also worth bearing in mind that publicly traded stocks are traded robustly and are based upon long-term projections of profitability that may seem unrealistic. Google currently has a market capitalization of about $\$ 175$ billion, ${ }^{225}$ with revenues of only $\$ 27$ billion and net income available to common shareholders of about $\$ 8$ billion. ${ }^{226}$ In such a fast-moving industry, what exactly makes people think Google's profitability is so sustainable for five, ten, twenty, or forty years as to warrant this size of investment, especially in a rapidly changing industry such as information technology? How do people even hazard a guess as to what the industry will look like two or three decades from now, and whether Google will even exist, let alone be as dominant then as it is now? Analysts will cite statistics and compare Google's figures with

222. See supra notes 77-81 and accompanying text.

223. Lauren Morello, Measuring Greenhouse Gases, a New Business Venture, ClimATEWIRE (Jan. 12, 2011), http://www.eenews.net/climatewire/print/ 2011/01/12/2 (paid subscription).

224. See Quirin Schiermeier, The Real Holes in Climate Science, 463 NATURE 284, 284 (2010).

Researchers say it is difficult to talk openly about holes in understanding. "Of course there are gaps in our knowledge about Earth's climate system and its components, and yes, nothing has been made clear enough to the public," says Gavin Schmidt, a climate modeller at NASA's Goddard Institute for Space Studies in

Id. New York.

225. Google Inc. (GOOG), YAHOO! FIN., http://finance.yahoo.com/q/ks?s=GOOG (accessed Aug. 10, 2011).

226. Id. 
those of other companies, but in the end, investors believe that somehow, this company is sustainable for many years.

In markets, we cope with uncertainty by somehow taking our best guesses. This is what is needed in climate science. The lack of a credible institution that forces us to take our best guess about future climate conditions, in the face of uncertainty, is precisely the problem with climate policy. Are the data flaws so great that costly action is premature, as the climate skeptics argue, or are the risks so great that much more immediate action is warranted, as climate scientists generally argue? Doing nothing is the default policy. Doing nothing is also the stock market's equivalent of stashing one's money in his mattress, a myopic strategy that almost every investor recognizes as a sure-fire money-loser.

\section{E. What Kinds of Information Will Be Reflected in Trading Activity?}

Although the primary purpose of this proposal is to process, evaluate, and generate climate science, the trading activity of future permits will also reflect the emergence of other important pieces of information. Many kinds of events, not just scientific discoveries about climate science, have the potential to affect forecasts of the number and frequency of dangerous climate outcomes. This Section discusses some of the types of events that may affect trading prices. These events create unwelcome side effects, mixing the impacts of climate science with those of other events, thereby diluting the signal for climate science. Ideally, this proposal would filter out both developments unrelated to discoveries and evaluations unrelated to climate science, but for some of these events it may be difficult to separate out the effects of these events. ${ }^{227}$ To some extent, dilution of the signal for climate science is unavoidable.

This inevitability underscores again the need to keep the index simple and to use it to focus on fundamental indicators of

227. There is the possibility that the effects of some events that could affect climate outcomes could be captured by a separate contingent prediction market. Separate continent markets could allow for trading in shares of outcomes only if a specified condition occurred. So, for example, if the election of Sarah Palin as U.S. President were likely to lead to a dismantling of this program, then a separate contingent prediction market could be established for those outcomes contingent upon her election. For a review of contingent prediction markets, see Wolfers \& Zitzewitz, supra note 82, at 122-24. 
climate change. But beyond that, maybe it is not such a bad thing that this prediction market captures events other than just climate science. Again, in the seemingly constant chatter of information about all kinds of developments in climate science, technology, and policy, what is the layperson to make of it all? A prediction market can help. After all, a wide variety of things are said about addressing climate change (or not), and there is, again, precious little rational evaluation of the seriousness of these things, and there is still a lay public wondering what to think. ${ }^{228}$

Viewed in this vein, a prediction market for climate outcomes could aid in the more rational discussion of technological developments and their potential to reduce greenhouse gases. A prediction market could actually act as an arbiter of the quality of climate technologies, a role that markets have historically played with great effectiveness. Because the index is keyed to climate outcomes, this prediction market would judge climate technologies ultimately by their ability to change the climate. This information is, like credible evaluations of climate science, currently scarce.

Climate technologies currently fall into two very broad categories: (1) mitigation technologies, which reduce emissions, or (2) post-emission geo-engineering strategies to directly reduce the risk of climate change, either by physically or chemically removing greenhouse gases from the Earth's atmosphere or reducing the heat-generating effects of solar radiation. ${ }^{229}$ Carbon capture and storage (CCS) technology is an example of an emissions reduction technology. CCS aims to extract the $\mathrm{CO}_{2}$ from fossil fuels (mostly coal) and store it in underground caverns or some other geologically appropriate space, where it will remain for an effective eternity and avoid affecting the Earth's climate. ${ }^{230}$ What should we make of this technology? Perhaps more pertinent, how much should governments spend to subsidize the development of this technology? The answers offered to this question have not been sensible, except in a nakedly political sense.

Some in Congress seem to have fallen in love with CCS technology, and some have even likened its development to

228. See supra notes 1-2 and accompanying text.

229. See supra note 112.

230. Carbon Dioxide Capture and Storage (CCS), WoRLD RESOURCES Inst., http://www.wri.org/project/carbon-capture-sequestration (last visited Feb. 25, 2011). 
that of the atomic bomb, necessitating a super-research effort. In a 2009 floor speech, U.S. Senator Lamar Alexander said, "we should launch another mini-Manhattan Project and reserve a Nobel Prize for the scientist who can get rid of the carbon from existing coal plants, because coal provides half our energy."231 This seems overenthusiastic. The most prominent pilot American CCS project, FutureGen, ${ }^{232}$ has lost its two biggest industry backers, AEP and the Southern Company. ${ }^{233}$ This is a shocking development involving the two largest coal users in the United States. ${ }^{234}$ And yet, FutureGen has suffered a neverending series of twists and turns, the news alternately holding out the promise of rescuing the coal industry and at times sounding the death knell of the whole idea. ${ }^{235}$ How seriously do we take information about advances and setbacks with respect to CCS? Markets may provide a badly needed reality check.

A prediction market for climate outcomes would also evaluate geo-engineering technologies and perhaps be an even better arbiter, since the only thing that geo-engineering projects are supposed to do is reduce the concentration of greenhouse gases. One technology currently under consideration is "air capture" technology, which literally sucks $\mathrm{CO}_{2}$ right out of the air for sequestration. ${ }^{236}$ This is accomplished by exposing some alkaline chemical compounds capable of reacting with ambient $\mathrm{CO}_{2}$ to form new compounds, from which the absorbed $\mathrm{CO}_{2}$ can be captured and stored. ${ }^{237}$

231. 155 CONG. REC. S4529 (daily ed. Apr. 22, 2009) (statement of Sen. Lamar Alexander), available at http://frwebgate.access.gpo.gov/cgi-bin/ getpage.cgi?position $=$ all\&page $=$ s $4529 \&$ dbname $=2009 \_r e c o r d$.

232. FutureGen is a proposed pilot carbon capture and storage project that aims to capture the $\mathrm{CO}_{2}$ emissions from a midwestern coal-fired power plant, most recently slated for construction in Morgan County, Illinois. See, e.g., FutureGen 2.0 Project, FUTUREGEN ALLIANCE, http://www.futuregenalliance.org/futuregen-20-project (last visited June 3, 2011); Christa Marshall, FutureGen Gets a Storage Site, ClimATEWIRE (Mar. 1, 2011), http://www.eenews.net/climatewire/print/ 2011/03/01/4 (paid subscription).

233. Mark Chediak \& Katarzyna Klimasinska, AEP to Exit Clean-Coal Project, TUlSA WORLD, June 25, 2009, at E2. The U.S. Department of Energy has nevertheless pledged one billion dollars in support of the project. Christa Marshall, DOE Commits \$1 Billion to FutureGen Project, ClimateWIRE (Sept. 29, 2010), http://www.eenews.net/climatewire/print/2010/09/29/5 (paid subscription).

234. Chediak \& Klimasinska, supra note 233.

235. Compare id. with Marshall, supra note 233.

236. David W. Keith, Why Capture $\mathrm{CO}_{2}$ from the Atmosphere?, 325 SCIENCE 1654,1654 (2009).

237. Id. at 1655 . 
The concentration of $\mathrm{CO}_{2}$ in the air is very low, ${ }^{238}$ so capturing the $\mathrm{CO}_{2}$ directly from the air is an inherently clumsy engineering task. ${ }^{239}$ However, air capture technology can be deployed anywhere, so it can be strategically placed near geologic formations susceptible of $\mathrm{CO}_{2}$ storage and can utilize renewable energy technologies away from the grid. ${ }^{240}$ Air capture technology is more clearly benign and free from sideeffects than other geo-engineering technologies that have been proposed. ${ }^{241}$ Finally, air capture technology can be employed unilaterally and is thus a way around the seemingly intractable international diplomacy problems that plague climate change. ${ }^{242}$ But it is expensive-even more so than $\mathrm{CCS}^{243}$ How excited should we be about this technology?

This proposal introduces a financial incentive for people to critically evaluate these and other truly climate-altering technologies. As some people have become discouraged by the one-step-forward-two-steps-backward pace of international climate negotiations, the ability of geo-engineering technologies to allow unilateral action is, going forward, going to remain a policy option. Market evaluations of the feasibility of these technologies cannot be a bad thing. A market signal may provide policymakers information about what markets think about the potential of certain technologies to affect climate outcomes. It could be that the most significant thing a market in future permits can do is yawn while Washington pundits and overnight physicists in the U.S. Congress scream, "this is a game-changing technology!"244

238. Carbon dioxide concentrations are currently at about 390 parts per million. Trends in Atmospheric Carbon Dioxide, EARTH SYs. RES. LABORATORY, http://www.esrl.noaa.gov/gmd/ccgg/trends (last visited Feb. 26, 2011).

239. Keith, supra note 236 , at $1654-55$.

240. Id. at 1655 .

241. For example, one geo-engineering idea that has been discussed is "iron fertilization," the seeding of oceans with iron, to facilitate the growth of $\mathrm{CO}_{2}$ absorbing phytoplankton. While this could result in the absorption of $\mathrm{CO}_{2}$, it would also likely dramatically alter the balance of ocean life by changing, among other things, the acidity of the ocean. See HEnson, supra note 48, at 331.

242. Scott Barrett, Climate Treaties and Backstop Technologies 4 (CESifo, Working Paper No. 3003, 2010), available at http://www.ifo.de/portal/pls/portal/ docs/1/1185648.PDF.

243. Id.

244. Supposed "game-changing" technologies have included: electric vehicle batteries, Jason Plautz, States See Rebirth in Battery Manufacturing, GREENWIRE (July 12, 2010), http://www.eenews.net/public/Greenwire/2010/07/12/11 (paid subscription) (quoting a Michigan Economic Development Corporation as stating, "This is a game-changer for Michigan. It's the birth of an industry"); electricity storage technology generally, Lea Radick, Some Energy Storage Solutions May Be 
In addition to providing information about technologies, a prediction market might also provide information about policy developments. This is not altogether welcome, as it dilutes the signal for climate science, but again, it is unavoidable. The political rise of climate skeptics may dampen prices because of the prospect of their dismantling this program if one of them becomes President. One response to this has already been made: that this program will generate vested interests that could make its termination politically costly. ${ }^{245}$ Another response is that if a climate skeptic is elected President and this program is terminated, then we are no worse off than we would be never having had this program and perhaps better off for the information collected while the program was in place.

To again put this inevitability in a more positive light, a prediction market might be helpful in interpreting policy events. Markets may signal their beliefs in the significance of certain actions or statements. For example, the widely criticized behavior of Chinese representatives at the Copenhagen meeting, seeming to signal a disinterest in agreeing to climate action, ${ }^{246}$ might be a signal that China is

'Game-Changers,' Industry Leaders Say, ClimATEWIRE (Mar. 13, 2009), http://www.wbcsd.org/Plugins/DocSearch/details.asp?ObjectId=MzM2ODU; shale gas, Mike Soraghan, Shale Plays Create 'New World' for Energy Industry, GREENWIRE (Mar. 11, 2010), http://www.eenews.net/Greenwire/print/2010/03/11/1 (paid subscription) ("Nearly every presenter at the conference has found a way to describe shale as a 'game changer.' "); small nuclear reactors, Katherine Ling, House Panel to Focus on Small Reactors, Future R\&D at DOE, ENV'T \& ENERGY DAILY (May 17, 2010), http://www.eenews.net/EEDaily/print/2010/05/17/10 (paid subscription); nuclear reactors that burn spent fuel, Peter Behr, A Reactor That Burns Depleted Fuel Emerges as a Potential 'Game Changer,' ClimateWIRE (Feb. 23, 2010), http://www.eenews.net/climatewire/print/2010/02/23/1 (paid subscription); ocean thermal power, Saqib Rahim, Is 'Ocean Thermal' Power Ready for Its Day in the Sun?, ClimateWIRE (Feb. 11, 2009), http://www.earthportal.org/news/?p=2165; a transmission line linkage, Peter Behr, Proposal to Link the Nation's Grid Sparks a Debate, ClimateWIRE (Feb. 3, 2010), http://www.eenews.net/climatewire/print/2010/02/03/1 (paid subscription), Peter Behr, An Electric 'Game Changer' Gets FERC Scrutiny, N.Y. TIMES, Dec. 23, 2009, http://www.nytimes.com/cwire/2009/12/23/23climatewire-an-electric-gamechanger-gets-ferc-scrutiny-48247.html; and General Motors' plug-in hybrid vehicle, Josh Voorhees, Plug-in Hybrids Likely to Stay Expensive for DecadesReport, GREENWIRE (Dec. 14, 2009), http://www.eenews.net/Greenwire/print/ 2009/12/14/15 (paid subscription).

245. See supra Part IV.B.2.

246. During negotiations at the Copenhagen Conference of Parties, Chinese Premier Wen Jiabao twice snubbed world leaders by sending an aide instead of attending in person, prompting President Obama to ask, "Mr. Premier, are you ready to see me?" Peter Maer, Impromptu Moments Shaped Copenhagen Accord, CBSNEws.COM (Dec. 24, 2009, 12:02 PM), http://www.cbsnews.com/stories/2009/ 12/20/politics/main6000506.shtml. 
prepared to live in a future world with climate change. On the other hand, China has raced past all other countries (including the United States) in investment in renewable energy technologies, possibly signaling its preparation for a low-carbon future. ${ }^{247}$ Which way is China heading? It is not a crazy thought to entertain that a prediction market might make more objective guesses and better projections than climate pundits and China-watchers.

\section{F. The Politics of Carbon Taxes and Cap-and-Trade}

Carbon taxes will continue to be controversial. My other work on carbon taxes acknowledges these political realities. ${ }^{248}$ At the same time, there is a set of countervailing realities that American politicians will have to confront eventually. First, rising deficits and the now ever-present concern over sovereign debt problems may push carbon taxes out of the taboo category and into the "necessary evil" category, as jurisdictions look for ways to bridge their yawning budget gaps. ${ }^{249}$ Second, if other nations begin to cobble together some sort of climate policy (as Europeans will continue to do) and foster a low-carbon economy (as China's investments in renewable energy seem to be aimed at doing), then Americans, Canadians, and other laggards may find themselves at political and economic disadvantages. Finally, a carbon tax can be made to start out (with present climate outcomes) at a low level. A low-enough-indexed carbon tax could conceivably fly under the threshold of indignation that could doom most climate policies. A \$5-per-ton tax, for example, translates to a five-cent increase in the price of a gallon of gasoline. ${ }^{250}$ For a household that consumes the 2001

247. Lisa Friedman, China Leads Major Countries with \$34.6 Billion Invested in Clean Technology, CliMATEWIRE (Mar. 25, 2010), http://www.eenews.net/ climatewire/print/2010/03/25/1 (paid subscription) (citing PEW CHARITABLE Trusts, WHO'S WINNING THE CleAN ENERgY RACE? (2010), available at http://www.eenews.net/public/25/14924/features/documents/2010/03/25/document_ cw_03.pdf).

248. HsU, supra note 105, at 181-91.

249. See, e.g., Christa Marshall, British Columbia Survives 3 Years and $\$ 848$ Million Worth of Carbon Taxes, ClimateWire (Mar. 22, 2011), http://www.eenews.net/climatewire/2011/03/22/1 (paid subscription) (" 'A huge question we are facing is how to deal with budget problems,' [University of Michigan professor Barry] Rabe said. 'Where are states going to get money? They don't have many choices, and carbon is one place to look.'”).

250. One U.S. gallon of gasoline contains about $2.42 \mathrm{~kg}$ of carbon. N.C. CoOP. EXTENSION, CONVERSION FACTORS FOR BIOENERGY (2008), available at http://www.ces.ncsu.edu/forestry/biomass/pubs/WB008.pdf. One kilogram of 
U.S. average of 1143 gallons per year, ${ }^{251}$ there is an average increase of about $\$ 56$ per year in fuel costs. At some point, shrill cries of a carbon tax increasing gasoline prices will meet the reality that its actual cost would be relatively modest.

Perhaps most importantly, this proposal would enjoy one critical political and optical advantage over other carbon tax proposals. Indexed as it is to destructive climate outcomes, all or a portion of proceeds of this carbon tax could be earmarked for disaster assistance for victims of climate outcomes. It could be considerably easier to sell a carbon tax that is viewed as being a funding mechanism for climate-related disaster (or even disaster unrelated to climate) such as hurricanes or droughts. Such a tax seems much more linked to ameliorating a problem than it is to a simple consumption tax burden and a government money-grab.

More generally, carbon taxes must, for lack of any alternatives, soon emerge as an acceptable option. It is tempting to dismiss any carbon tax as politically unpalatable at this juncture. But even a moment's reflection would suggest considerable potential for introducing a carbon tax. In the Canadian province of British Columbia, North America's first carbon tax is being phased in from a level of about $\$ 10(\mathrm{Cdn})$ per ton up to about $\$ 30(\mathrm{Cdn})$ per ton, over five years, ending in 2012. ${ }^{252}$ The governing political party that introduced the carbon tax, the Liberal Party, has survived the political storm, even picking up some support along the way, ${ }^{253}$ suggesting that the resistance to a carbon tax in this range may not be immovable. One key to the success of the Liberal Party of British Columbia is that it was the more conservative of the two parties vying for power in the province. By outflanking its

carbon is 5.34 pounds, which equals 0.00266 short tons. The molecular weight of carbon is 12 , while the molecular weight of $\mathrm{CO}_{2}$ is 44 . See Calculate Molecular Weight-Molar Mass Calculator, WEBQC.ORG, http://www.webqc.org/mmcalc.php (last visited May 3, 2011). Burning one gallon of gasoline thus emits 0.00266 short tons of carbon and 0.00978 short tons of $\mathrm{CO}_{2}$. A carbon tax of five dollars per ton of $\mathrm{CO}_{2}$ would thus result in a carbon tax of 4.89 cents per gallon.

251. ENERGy InFo. AdMIN., HouseHold VEHICLES ENERGY USE: LATEST DATA AND TRENDS 57 tbl.A2 (2005), available at http://www.eia.gov/emeu/rtecs/ nhts_survey/2001/tablefiles/0464\%282005\%29.pdf. This only reports average consumption among U.S. households that own a car. The average per all households would be lower.

252. Carbon Tax Act, S.B.C. 2008, c. 40 (Can.), available at http://www.bclaws.ca/EPLibraries/bclaws_new/document/ID/freeside/ 00_08040_01.

253. HSU, supra note 105, at 187. 
more liberal and environmentally active rival party, the Liberal Party split the voters of its rival along environmental lines and undermined the rival's traditionally solid and large base of environmental voters. ${ }^{254}$ Despite the label of "Liberal" for the governing party, American conservatives might take note of this political success.

\section{CONCLUSION}

It is no exaggeration to say that markets inexplicably work. How exactly does information travel from one market participant to another, what form does that information take, and how does it get translated into prices? Nobody knows. As economist Maureen O'Hara has quipped, "while markets appear to work in practice, we are not sure they work in theory." 255 This proposal aims to tap into the mysterious efficiency of markets. This Article has left a number of details to future thought and design but has sketched out the basic parameters of a simple idea: Impose a carbon tax, specify that the carbon tax will be indexed to some climate outcomes, and offer to the taxed entities the opportunity to purchase permits to emit in lieu of paying the tax. These permits would be tradable after their initial auction. The idea of this proposal is to use the trading activity of the future emissions permits to generate some credible forecasts about what the indexed carbon tax will be and, hence, what climate outcomes will be.

We are probably better off not giving in to cynicism when considering the arguments of those with whom we disagree about climate science, however tempting it is to think that the "other side" is just nuts or corrupt. However, the vast uncertainties, the enormous political stakes involved, and the very personal core values implicated by the problem of climate change, not to mention the large investments that both climate advocates and climate skeptics have in their particular substantive positions, give rise to a situation in which anybody can accuse anybody of taking a subjective interpretation of climate science. It is truly challenging under these circumstances to take a benign view of those with whom we disagree. This proposal, more than even addressing the

254. Id.

255. Maureen O’Hara, Making Market Microstructure Matter, Fin. MGMT., Summer 1999, at 83, 83. 
problem of reducing greenhouse gases, addresses the question of whom we truly believe and how sure we are of our beliefs.

Markets are inherently imperfect, so the information generated by this proposal will be imperfect. It is not as if this cap-and-trade market will reveal the true climate science. Rather, what this proposal does is provide objective information about what others think. This information network aspect, similar to the information network embedded in market prices, is feedback more than it is information, and it serves as a challenge to our beliefs. While McKitrick's proposal of a temperature-indexed carbon tax is meant to tap into nature as an "arbiter," this proposal goes further and taps into both nature and markets as arbiters. Nature gets to determine the level of the carbon tax, but markets get to make important forecasts about what nature will do in the future.

\section{APPENDIX}

\section{A. Construction of the Carbon Tax Index}

\section{Global Mean Temperature}

As noted in Part IV.A.3.i, constructing a global mean temperature statistic raises thorny issues because temperature-taking is not uniform across the planet, and in some countries where it is taken the data are spotty and unreliable. Moreover, countries are sometimes reluctant to release their raw climate data except with confidentiality agreements that protect their proprietary interests. ${ }^{256}$ How does one "clean" or adjust data that are obviously faulty without being accused of tampering? This has been the plight of the Climatic Research Unit (CRU) at the University of East Anglia and its beleaguered director, Dr. Phil Jones, foci of the "Climategate" controversy. ${ }^{257}$ The CRU data are compilations of raw temperature readings compiled into $5^{\circ} \times 5^{\circ}$ grid boxes for most of the land surface of the Earth. ${ }^{258}$ While CRU makes its compilation publicly available, it irked climate skeptics by

256. Telephone interview with Xuebin Zhang, Research Scientist, Env't Can. (Feb. 17, 2011).

257. See supra notes 15-17 and accompanying text.

258. Phil Jones \& Mike Salmon, Temperature, Climatic Res. Unit, U. E. ANGLIA, http://www.cru.uea.ac.uk/cru/data/temperature (last updated Jan. 2011). 
refusing to divulge its raw data. ${ }^{259}$ The problem was that CRU's raw data from weather stations throughout the world were provided by the national meteorological services of each country under the condition that the data not be publicly disseminated. ${ }^{260}$ Even demands by climate skeptics that CRU share its code would allow people to reverse engineer the publicly available data and re-create the raw data, violating the confidentiality agreements.

Other datasets exist, ${ }^{261}$ but they are not free of controversy either. McKitrick proposes using an average temperature calculated from a dataset maintained by Roy Spencer and John Christy, researchers at the University of Alabama at Huntsville (UAH), which uses publicly available data from NOAA satellites and infers temperatures at different altitudes. ${ }^{262}$ The controversy surrounding this dataset stems from its deployment in past studies that seem to have shown no increase in global temperatures. ${ }^{263}$ Frank Wentz and Matthias Schabel argued that part of the cooling trend can be attributed to the orbital decay of the satellites from which the readings were taken. ${ }^{264}$ Spencer and Christy made adjustments to their analysis but have also made other adjustments that suggest that there is no warming trend, at least in the troposphere above ground level. ${ }^{265} \mathrm{~A}$ subsequent special report from the National Academy of Sciences concluded that it was possible that both sets of data were correct - that the surface temperatures may have warmed more quickly than tropospheric temperatures. ${ }^{266}$ Subsequent

259. See supra note 15.

260. Lauren Morello, 'Climategate' Scientist Admits 'Awful Emails,' But Peers Say IPCC Conclusions Remain Sound, ClimateWIRE (Mar. 2, 2010), http://www.eenews.net/climatewire/2010/03/02/2 (paid subscription); see also supra note 15.

261. For a brief description of the main datasets, see HENSON, supra note 48, at $178-80$.

262. McKitrick, supra note 101, at 117-18. McKitrick's specific proposal would average the temperature of the tropical troposphere, the lowest layer of the atmosphere-the one touching the Earth's surface-over the tropical belt (between the Tropic of Capricorn and the Tropic of Cancer) around the Earth. Id.

263. Spencer \& Christy, supra note 14, at 1558.

264. Frank J. Wentz \& Matthias Schabel, Effects of Orbital Decay on SatelliteDerived Lower-Tropospheric Temperature Trends, 394 NATURE 661, 661 (1998).

265. John R. Christy et al., Tropospheric Temperature Change Since 1979 from Tropical Radiosonde and Satellite Measurements, 112 J. GEOPHYSICAL RES. D06102, 1 (2007).

266. PANel ON Reconciling Temperature Observations, BD. ON Atmospheric Scis. \& Climate, Reconciling Observations of Global 
analyses of the data now appear to have reconciled them with other datasets. ${ }^{267}$

These are live controversies that need to be addressed, but for purposes of indexing a carbon tax, they seem susceptible to resolution. There is no disagreement in principle, even between climate scientists and climate skeptics (who of course include scientists), that the use of some global temperature measure is a fundamental indicator of climate change. At a minimum, the UAH data, which have now been tested and reconciled with other datasets, and which Professor McKitrick proposes be used for an index, would seem to be a reasonable beginning point.

\section{Days of Unusually High or Low Temperatures}

"Unusual" implies some comparison with historical standards and would obviously be location specific, as the average for a polar location would be much lower than the average for a tropical one. Fortunately, the Expert Team on Climate Change Detection and Indices (ETCCDI), a working group of climate scientists attempting to collect and process temperature data throughout the world, ${ }^{268}$ provides a head start on thinking about temperature extremes. Seeking to process raw temperature and precipitation data in a way that does not violate confidentiality agreements that inevitably come with the data, the ETCCDI has developed an index of twenty-seven outcomes (the ETCCDI calls them "indices") through which to run the data and create a separate database. ${ }^{269}$ In other words, the "indices" are a transformation of the raw data-a way of presenting the same information without the actual raw data.

Included in the ETCCDI basket of "indices" are a number of statistics aimed at measuring the duration and severity of temperature and precipitation anomalies (both extreme

\footnotetext{
TEMPERATURE CHANGE 2 (2000), available at http://www.nap.edu/ catalog/9755.html.

267. Henson describes the UAH data and documents the controversy among climate scientists on the reliability of the UAH dataset. HENSON, supra note 48, at $183-85$.

268. Overview, ExPeRT TeAm on Climate Change Detection \& InDices, http://cccma.seos.uvic.ca/ETCCDI/index.shtml (last updated Sept. 15, 2009).

269. Climate Change Indices, Expert TeAm on Climate Change DeteCtion \& INDICES, http://cccma.seos.uvic.ca/ETCCDI/list_27_indices.shtml (last updated Sept. 15, 2009).
} 
precipitation and drought). ${ }^{270}$ Prominent among the indices are two that suit the purpose of this proposal well:

1. The percentage of days in which the daily maximum temperature was higher than ninety percent of the following: the daily maximum temperature readings for that same calendar day in the base years 1961 to 1990 , plus the two days before and the two days after that calendar day, also in the years 1961 to $1990 ;{ }^{271}$ and

2. The percentage of days in which the daily minimum temperature was lower than ninety percent of the same set of temperature readings. ${ }^{272}$

For example, if the ninetieth percentile of all daily maximums from June 13 to June 17, 1961 to 1990 , was $88^{\circ}$, then any June 15 with a daily maximum temperature of $89^{\circ}$ or more would be counted for purposes of this index as an "unusually high" day. By the same token, if the tenth percentile for all daily minimums from March 2 to March 6, 1961 to 1990 , was $13^{\circ}$, any March 4 on which the daily minimum was $12^{\circ}$ or lower would be counted as an "unusual low."

These two indices measure the extremes of heat and coldthe hottest it gets on hot days, and the coldest it gets on cold days. It is also possible to include some measure of the persistence of such heat and cold by including the minimum temperature on hot days ${ }^{273}$ and the maximum temperature on cold days. ${ }^{274}$ Using the same method of comparing daily measurements against a historical five-day window centered upon the calendar day in which the measurement is taken, the ETCCDI aims to provide some measurement of how persistently hot and cold days can be without relief.

The ETCCDI's work is a work in progress. In constructing an index, it is also important to consider how to choose locations from which data will be processed and become part of the index. As the ETCCDI continues to work with and process datasets, this question is also one that requires deft resolution.

270. Id. (indices 17-27).

271. Id. (index 13).

272. Id. (index 10).

273. Id. (index 12).

274. Id. (index 11). 


\section{Extreme Rainfall and Drought Events}

Even "flooding" and "drought" are somewhat subjective terms and require some formal definition. A number of indices taking into account drought are possible, but it is useful to refer again to the work of the ETCCDI. As with \#2 (days of unusually high or low temperatures), some transformation of raw data is necessary. It seems desirable to compare data with historical records of precipitation in the comparable time of year so that the precipitation in wet areas such as coastal British Columbia are evaluated in the context of how wet it has been in the past. With dry areas, however, extreme and prolonged dryness render this way of counting dry days statistically difficult. If it has historically been bone-dry in Phoenix every single summer for the entire period of 1961 to $1990,{ }^{275}$ there will be no ninetieth percentile, or any other percentile. There is no such thing as "unusually dry" when looking at summers in Phoenix.

Consistent with the objectives of this climate index, two statistics under consideration by the ETCCDI seem helpful in measuring extreme rainfalls and droughts:

1. The total number of days in which the precipitation is greater than ninety-nine percent of all wet days (defined as getting more than one millimeter of rain, just a very small amount) in the entire period from 1961 to 1990. In other words, extreme rain is evaluated against the wettest days in the entire thirty-year period from 1961 to $1990 .^{276}$

2. The length of droughts, i.e., the number of consecutive days in which there was less than one millimeter of rain. ${ }^{277}$

The Bureau of Meteorology in Australia is able to get around the statistical dryness problem by aggregating data over a region and averaging them over an entire year. The Bureau defines a drought as rainfall over three consecutive months that is in the lowest ten percent of what has been recorded for that region in the past. ${ }^{278}$ Of course, droughts could be extremely long periods of time with very limited

275. From 1971 to 2000, average rainfall in Phoenix was as follows: April, 0.25 inches; May, 0.16 inches; June, 0.09 inches; July, 0.99 inches; and August, 0.94 inches. Judy Hedding, Does It Rain in Phoenix, AZ?, ABouT.com, http://phoenix.about.com/od/weather/qt/rain.htm (last visited May 4, 2011).

276. Climate Change Indices, supra note 269 (index 26).

277. Id. (index 23).

278. Climate Glossary: Drought, Bureau Meteorology, Australian Gov't, http://www.bom.gov.au/climate/glossary/drought.shtml (last visited Jan. 3, 2011). 
rainfall. The economically vital Murray-Darling basin in Australia experienced almost a decade of low rainfall ${ }^{279}$ (though not all of it within the definition of "drought"). ${ }^{280}$

\section{Sea Level Rise}

As oceans warm along with the rest of the planet, they expand in volume, accounting for a significant part of sea level rises to date. ${ }^{281}$ This much is not in doubt, but the contribution of melting, land-based glaciers is cause for concern and may cause oceans to rise by several meters rather than several inches. $^{282}$

As with other climate indicators meant to measure something on a planetary scale, measuring sea levels is surprisingly difficult. Because of tectonic changes in land and ocean beds, using land as a reference point is flawed, so using tidal gauges-putting a measuring stick in the ocean and taking periodic measurements-is inadequate. ${ }^{283}$ More advanced systems now use satellite data to measure mean sea levels with error of less than one millimeter. ${ }^{284}$ For purposes of measuring ocean level rises, satellite data collected by several governments do not, unlike other climate data, seem to be controversial.

\section{Ocean Acidity}

Measuring the average $\mathrm{pH}$ of the world's oceans is not, at this time, a particularly controversial exercise, in part because so little attention has been focused on this subject. ${ }^{285}$ With oceans occupying seventy-one percent of the Earth's surface, ${ }^{286}$ and given the importance of ocean life to humankind, ocean chemistry would appear to be a vital statistic to include in an index of climate outcomes.

279. Annual Australian Climate Statement 2010, Bureau Meteorology, AUSTRALIAN GOV'T (Jan. 5, 2011), http://www.bom.gov.au/announcements/ media_releases/climate/change/20110105.shtml.

280. Drought Statement, Bureau Meteorology, Australian Gov'T (Dec. 3, 2008), http://www.bom.gov.au/climate/drought/archive/20081203.shtml.

281. IPCC FOURTH ASSESSMENT, supra note 26, at 408.

282. HENSON, supra note 48, at 111-18.

283. Id. at 107-08.

284. Id. at 108.

285. Id. at 124 .

286. Ocean, NAT'L OCEANIC \& ATMOSPHERIC ADMIN., http://www.noaa.gov/ocean.html (last visited May 4, 2011). 


\section{Hurricanes Above a Certain Intensity Level}

Hurricane intensity is commonly measured using the Saffir-Simpson Hurricane Wind Scale, which rates hurricane strength on the basis of the maximum sustained wind speed during a hurricane. ${ }^{287}$ A category 3 hurricane is one in which the peak wind speeds are 111 to 130 miles per hour, category 4 is one in which peak speeds are 131 to 155 , and category 5 is one in which the peak speeds are greater than 155 miles per hour. ${ }^{288}$ A "major" hurricane is a category 3, 4, or 5 storm. ${ }^{289}$ Between 1900 and 2000, twenty-five of thirty-one of the deadliest hurricanes were category 3 or higher, and ten of the twelve deadliest were category 4 or higher. ${ }^{290}$

In most cases, the bulk of the damage from hurricanes comes from the storm surges that inundate coastal areas and account for the vast majority of deaths directly attributable to hurricanes. ${ }^{291}$ The old Saffir-Simpson scale used to incorporate central pressures and storm surges as part of the index. ${ }^{292}$ To avoid confusion, however, and because storm surges vary greatly by topography, the index was simplified to only include hurricane peak wind speeds. ${ }^{293}$ Using a simpler index, focusing on wind speed, would be consistent with the objectives of this index of climate outcomes.

Counting hurricanes and monitoring their wind speeds have been done uncontroversially, if inconsistently, for over a century. A number of hurricane-tracking sites exist, but the best global compilation of hurricane data is maintained by a private security management firm, Unisys. ${ }^{294}$ Unisys compiles information about hurricanes in each of the six major oceanic regions, collecting data from a number of national and international sources. ${ }^{295}$ While the relatively short history (for

287. Timothy Schott et al., Saffir-Simpson Team, The Saffir-Simpson Hurricane Wind Scale, NAT'L HURRICANE CENTER, http://www.nhc.noaa.gov/pdf/ sshws.pdf (last visited July 21, 2011).

288. Id. The National Hurricane Center's Saffir-Simpson Hurricane Wind Scale states that in hurricanes of category 4 or category 5 strength, "[c]atastrophic damage will occur," and that in hurricanes of category 3 strength, "[d]evastating damage will occur." Id.

289. Jarrell et al., supra note 187.

290. Id.

291. See id.

292. Schott et al., supra note 287.

293. Id.

294. Hurricane/Tropical Data, supra note 114.

295. Id. 
climate data) handicaps efforts to attribute hurricanes to climate change, it is clearly long enough to support construction of an index including hurricane data.

\section{B. Cap-and-Trade Permit Auction Schedule}

If 400 million permits for each vintage year were to be issued each of the forty years preceding the vintage date, ten million would have to be issued each year. So starting in the year 2012, ten million 2052 permits would be auctioned per year, ending in the year 2051. But what about all of the years prior to 2052? For some years, more than ten million permits for a vintage year would have to be issued. For 2014 permits, should the bulk of them be auctioned in 2012 or 2013? To maximize the amount of information garnered by this prediction market, and to make sure the permit markets are as healthy as possible, the bulk of them should be issued in 2012-390 million, with the remaining ten million to be auctioned in 2013. Also in 2012, 380 million permits to emit in 2014 would be auctioned, with ten million in each of the following years. In other words, 2012 should be the year in which all excess permits are issued, with ten million permits for every vintage year being issued in each successive year. The schedule is set forth below in Table 1. 
Table 1: Schedule of Permit Auctions

\begin{tabular}{|c|l|l|l|l|l|c|c|c|}
\hline Year of & \multicolumn{2}{|l}{ Vintage Years } \\
\cline { 2 - 9 } auction & 2013 & 2014 & 2015 & $\bullet \bullet$ & 2050 & 2051 & 2052 & 2053 \\
\hline 2012 & $400 \mathrm{~m}$ & $390 \mathrm{~m}$ & $380 \mathrm{~m}$ & $\bullet \bullet$ & $30 \mathrm{~m}$ & $20 \mathrm{~m}$ & $10 \mathrm{~m}$ & \\
\hline 2013 & & $10 \mathrm{~m}$ & $10 \mathrm{~m}$ & $\bullet \bullet \bullet$ & $10 \mathrm{~m}$ & $10 \mathrm{~m}$ & $10 \mathrm{~m}$ & $10 \mathrm{~m}$ \\
\hline 2014 & & & $10 \mathrm{~m}$ & $\bullet \bullet \bullet$ & $10 \mathrm{~m}$ & $10 \mathrm{~m}$ & $10 \mathrm{~m}$ & $10 \mathrm{~m}$ \\
\hline$\bullet$ & & & & & $\bullet$ & $\bullet$ & $\bullet$ & $\bullet$ \\
$\bullet$ & & & & & $\bullet$ & $\bullet$ & $\bullet$ & $\bullet$ \\
$\bullet$ & & & & & $\bullet$ & $\bullet$ & $\bullet$ & $\bullet$ \\
\hline 2049 & & & & & $10 \mathrm{~m}$ & $10 \mathrm{~m}$ & $10 \mathrm{~m}$ & $10 \mathrm{~m}$ \\
\hline 2050 & & & & & & $10 \mathrm{~m}$ & $10 \mathrm{~m}$ & $10 \mathrm{~m}$ \\
\hline 2051 & & & & & & & $10 \mathrm{~m}$ & $10 \mathrm{~m}$ \\
\hline 2052 & & & & & & & & $10 \mathrm{~m}$ \\
\hline
\end{tabular}

